\title{
Ground Filtering Algorithms for Airborne LiDAR Data: A Review of Critical Issues
}

\section{Xuelian Meng ${ }^{1,2} *$, Nate Currit ${ }^{1}$, and Kaiguang Zhao ${ }^{3}$}

1 Department of Geography, Texas State University-San Marcos, 601 University Drive, San Marcos, TX 78666, USA; E-Mail: currit@txstate.edu

2 Department of Geography, Texas A\&M University, 810 O\&M Building, College Station, TX 77843-3147, USA

3 Spatial Sciences Lab., Department of Ecosystem Science and Management, Texas A\&M University, College Station, TX 77843-3147, USA; E-Mail: zhaokg@tamu.edu

* Author to whom correspondence should be addressed; E-Mail: xm1001@txstate.edu.

Received: 4 January 2010; in revised form: 20 February 2010 / Accepted: 27 February 2010 /

Published: 22 March 2010

\begin{abstract}
This paper reviews LiDAR ground filtering algorithms used in the process of creating Digital Elevation Models. We discuss critical issues for the development and application of LiDAR ground filtering algorithms, including filtering procedures for different feature types, and criteria for study site selection, accuracy assessment, and algorithm classification. This review highlights three feature types for which current ground filtering algorithms are suboptimal, and which can be improved upon in future studies: surfaces with rough terrain or discontinuous slope, dense forest areas that laser beams cannot penetrate, and regions with low vegetation that is often ignored by ground filters.
\end{abstract}

Keywords: LiDAR; ground filtering; terrain; DEM; forest; urban; review

\section{Introduction}

LIght Detection And Ranging (LiDAR) technology determines the distance between ground objects and sensors by measuring the time a pulse of transmitted energy takes to return to the LiDAR sensor. When coupled with a ground referencing system, LiDAR sensors make dense, geo-referenced point elevation measurements [1-3]. Compared with traditional surveying and mapping systems, including photogrammetric systems, LiDAR technology provides a fast and accurate alternative [4-6] for 
mapping large areas at high resolution and is gradually being adopted as the primary technique to generate Digital Elevation Models (DEMs) [7-11]. The United States and some European countries have begun to utilize LiDAR systems to generate regional to national DEM products [1,12-14].

LiDAR techniques are arguably superior to traditional methods (e.g., photogrammetric techniques or automated image matching and elevation extraction techniques) for generating DEMs for at least five related reasons. First, the dense LiDAR point clouds enable generation of highly accurate, high resolution DEMs. Second, surface features can be extracted based on a height context analysis of the LiDAR points [15-21], enabling accurate mapping of surface features like buildings, trees, and even power lines and pipelines [15,22]. Additionally, a high density dataset allows users to apply a multi-scale or multi-resolution strategy of feature identification [21]. Third, it is easier to identify slight elevation changes using dense LiDAR point clouds, making it easier to map regions with little textural variations, including variations in the surface of vegetation canopies [15,23]. Fourth, vegetation canopy structure can be determined because LiDAR pulses penetrate the canopy and create multiple returns [24-27]. Different multiple return patterns during different seasons can also facilitate vegetation classification [28]. Lastly, LiDAR can be used to map ground elevations even in regions of dense vegetation because of multiple returns [15].

A large number of value-added products make LiDAR data valuable outside the realm of DEM generation. LiDAR data has been used for hydrologic modeling, coastal monitoring, forest inventory [29-31], urban three-dimensional visualization [32,33], land-cover and land-use classification, and object detection [34-37]. Furthermore, the integrated analysis of optical and LiDAR data is becoming an important research topic [ASPRS/MAPPS 2009 Specialty Conference for digital terrain mapping]. Successful integration of different sensors operating at different spatial and temporal resolutions will undoubtedly increase the number of LiDAR applications.

In nearly all LiDAR applications, ground filtering is a necessary step to determine which LiDAR returns are from the ground surface and which are from non-ground surface features. Distinguishing ground from non-ground can be a significant challenge in regions with high surface variability. Nevertheless, accurate DEMs can only be obtained if non-ground points are removed prior to interpolation to a raster DEM [2,12,38-40].

LiDAR is a relatively new technology, and users who are new to this data and ground filtering techniques often find it difficult to select from among the many ground filtering algorithms. Often, ground filtering algorithms perform best when specific surface conditions are met. Without understanding the assumptions of various ground filters, a new LiDAR data user will undoubtedly find it difficult to process LiDAR data. In this paper, therefore, we discuss criteria for selecting an appropriate ground filtering algorithm. We begin by discussing technical considerations for the development of ground filtering algorithms, including a general overview of filtering procedures, the role of study site characteristics in selecting a filtering algorithm, and methods used for accuracy assessment. Next, we review six categories of ground filtering algorithms and outline the factors that influence their accuracies. Lastly, we compare the accuracy of the Multi-directional Ground Filter (MGF) developed by the authors to published accuracy assessments of eight other filtering algorithms using standardized LiDAR datasets. We discuss the conditions that lead to the performance levels of each algorithm. This comparison and discussion is especially important for new users of LiDAR data 
seeking to select an appropriate ground filtering algorithm and for developers seeking to improve algorithms.

\section{Technical Considerations for Ground Filter Development}

\subsection{Ground Characteristics Used for LiDAR Ground Filtering}

LiDAR point measurementss are influenced by three components: bare ground, above-ground objects, and noise.

$$
M_{\text {sensor }}=E_{\text {ground }}+E_{\text {non-ground }}+M_{\text {noise }}
$$

where $\mathrm{M}_{\text {sensor }}$ is the measurements from the LiDAR sensor, $\mathrm{E}_{\text {ground }}$ is the elevation of ground. $\mathrm{E}_{\text {non-ground }}$ is the height of objects above ground. $\mathrm{M}_{\text {noise }}$ is the undesired measurements, such as the noise from sensors, airplanes, or birds.

In LiDAR data, the ground points are the measurements from bare-earth terrain that are usually the lowest surface features in a local area. Non-ground points are the measurements from the objects above the bare-earth terrain, such as trees, buildings, bridges, and shrubs. In order to appropriately identify ground points, it is important to understand the physical characteristics of ground points that differentiate them from non-ground points. Ground surfaces can be divided into four categories based on their physical characteristics.

1. Lowest Elevations. Ground surfaces are usually the lowest features in a local neighborhood. Many ground filtering methods based on this important characteristic search for the lowest elevations in a neighborhood to initialize the ground filtering process [1,21,38,41].

2. Ground Surface Steepness. Surface slope is generally lower between two neighboring bare ground points than between one bare ground and one non-ground point [38]. Hence, many ground filters define a point with slope larger than the maximum ground slope as a non-ground point $[2,38,42]$. The slope threshold value that distinguishes ground from non-ground points will likely differ for each surface type. Relatively flat urban surfaces may have a low threshold value, such as $30^{\circ}$. Complex surfaces such as mountain terrain or high relief forest canopy surfaces will have steeper slopes and may require a higher threshold to accurately distinguish ground from non-ground.

3. Ground Surface Elevation Difference. Because most bare-ground surfaces have few sharp changes in elevation, the elevation difference from a ground point to neighboring ground points is usually lower than the difference to neighboring non-ground points. Therefore, points having an elevation difference higher than a location specific threshold are probably non-ground points, such as shrubs, trees, or buildings [12,38,43,44].

4. Ground Surface Homogeneity. Ground surfaces are relatively continuous and smooth. Trees and buildings are the main non-ground features that should be removed from the measurements. But trees are usually less smooth in texture than bare ground and buildings [38] and may be removed based on morphologic characteristics [24].

These are the common characteristics that become assumptions of many ground filters. In some cases, ground surfaces may not have all of these characteristics, and filters may mislabel points as 
non-ground. For example, cliffs have sharp elevation changes and many filters fail to label them as ground.

\subsection{Difficult Ground Features for LiDAR Ground Filtering}

LiDAR ground filtering algorithms make different assumptions about ground characteristics to differentiate between ground and non-ground features. In reality, ground surfaces may have unique characteristics that confound certain ground filters depending on the location and terrain conditions. The following features often confound some ground filtering algorithms:

1. Shrubs, especially those below one meter

2. Short walls along walkways

3. Bridges

4. Buildings with different size and shape

5. Hill cut-off edges

6. Complex mixed covering

7. Areas combined with low and high-relief terrains

8. Lack of reliable accuracy assessment

Shrubs are common error points mis-labeled as ground surfaces. Shrub heights are usually less than one meter and so slope and elevation difference between the shrub and neighboring ground points are similar to those between ground points and neighboring ground points in variable terrain. Shrubs in urban areas are usually found as small patches dotting the ground. Similarly, short walls along steps, bridges, or fences in high relief areas, and other features often present in high-resolution urban LiDAR images are hard to distinguish from ground points. For certain filters (e.g., one-dimensional scanning filters), bridges may also cause difficulty because they are smoothly connected with ground surfaces.

Variable building sizes may cause problems for certain filters. Ground filters based on roving windows sometimes have difficulties removing large or small buildings. This difficulty arises because the filters separate points based on a comparison between the measured value and the estimated value within a certain neighborhood. If a large building completely contains a roving window, the points in the middle of the building may not be recognized as part of the building since there is no difference between the measured and estimated values.

Jagged hilly edges are difficult to identify for many ground filters. Although many natural surfaces have no sharp change in slope or elevation, certain terrain features do, like cliffs, shores, and riverbanks. Filters based on slope may mislabel ground with slopes larger than the maximum ground slope threshold as non-ground points. Likewise, areas of mixed low and high relief are challenging for ground filters because of the difficulty of selecting appropriate slope and elevation thresholds. Furthermore, most urban environments have a complex matrix of surface features that confound ground filtering algorithms, including buildings, trees, shrubs, bridges, short walls, and even wires.

\subsection{General Ground Filtering Procedures}

The four main procedures in LiDAR-based DEM generation are outlined below:

1. Error Filtering: Local LiDAR point outliers are often randomly distributed over a study area. 
Outliers may be caused by airplanes, birds, or the sensor itself. These points have unreasonably high or low elevation values and must be removed during preprocessing [1,24,45-47]. The simplest way to identify these outliers is to examine the frequency distribution of elevation values $[1,21,24]$. Less obvious random errors can be identified by comparing each point to a local elevation reference [1,24]. Often Delaunay Triangulation [1,24] is used to determine these less obvious outliers. Manual examination of the dataset is another viable option [47].

2. Interpolation, Resampling, or Reorganizing: Creating a raster dataset from the LiDAR point cloud is a necessary procedure for certain ground filtering algorithms. When a dataset is comprised of multiple flight lines of irregularly spaced LiDAR points, searching for neighboring points is a computationally intensive process [48]. Sometimes the search for neighboring points can be accelerated by creating a Triangulated Irregular Network (TIN) [1,21], but more often than not the point cloud is rasterized so that the dataset can be searched with simple kernels [1,49-53]. As mentioned previously, certain LiDAR filtering algorithms rely on raster-based search logic [50].

Multiple methods for rasterizing the LiDAR point cloud may be used depending on the local environmental conditions and the purpose of analysis. Simple methods assign the lowest point $[53,54]$, or the nearest point $[1,21,24]$, within an area to the pixel value. Other methods interpolate the pixel value $[48,55,56]$ using rectangular [38], or circular [12,38] kernel functions. TINs have also been used to define neighbors for interpolation [1,21,24].

3. Ground Filtering: Ground filtering is the process of separating ground and non-ground points or pixels $[1,47]$. A variety of methods are used, depending on the local environmental conditions. Directional scanning [1,2,24], morphology-based [46,61-63], interpolation-based [50,64-67], and segmentation-based [34,68-70] algorithms are fully discussed in the following sections and comparisons are made between them and the newly developed Multi-directional Ground Filtering (MGF) algorithm.

4. Generate DEM: A DEM is generated through interpolation of the ground points identified in the previous step [71,72]. Examples of popular interpolation methods include Inverse Distance Weighting [73], AMLE [74], Kriging [73,74], and hybrid methods that combine linear and non-linear interpolation [75]. Studies prove that complicated interpolation methods may not generate better results than simple ones [73].

Some researchers may not follow all the procedures outlined above depending their purpose, data characteristics and data quality. For example, if a user receives LiDAR data as well-interpolated raster images, they may not mention what kind of preprocessing they have done or what kind of method they use to interpolate the surface. Similarly, many filters combine the second and third procedures together, and some even combine the last three procedures together, which means they use the interpolation method to generate DEM and remove non-ground points while iterating through this process.

\subsection{Study Site Selection Considerations for Ground Filtering}

LiDAR ground filtering methods may have variable performance when applied to different areas and terrain conditions. Therefore, carefully selecting study sites is critical to adequately evaluate the 
performance of ground filtering algorithms. Table 1 shows the characteristics of numerous study sites used in different studies. Most filters in Table 1 work on the first return, and five filters function on the first or last return. The cell size is the resolution of interpolated datasets based on density and space between points. Most researchers developing and testing ground filters choose at least two study sites to assess the accuracy and reliability of their filters in different contexts.

Table 1. Comparative table of the selection and description of study sites.

\begin{tabular}{|c|c|c|c|c|c|c|c|}
\hline Example & Return & $\begin{array}{c}\text { Density } \\
\left.\text { (points } / \mathrm{m}^{2}\right)\end{array}$ & $\begin{array}{l}\text { Cell } \\
\text { size } \\
(\mathrm{m})\end{array}$ & $\begin{array}{l}\text { Area } \\
\left(\mathrm{km}^{2}\right)\end{array}$ & Context & Data selection & $\begin{array}{l}\text { Site } \\
\text { Number }\end{array}$ \\
\hline [2] & First & $\begin{array}{l}\text { Site 1: } 0.13 \\
\text { Site 2: } 0.72\end{array}$ & - & - & Low and high relief & $\begin{array}{l}\text { Low-relief urban }+ \text { sites with complex } \\
\text { covering with a maximum } 44.3^{\circ} \text { slope }\end{array}$ & 4 \\
\hline [38] & First & - & 1 & $\begin{array}{l}\text { Site } 1: 1.6 \\
\text { Site } 2: 3 \\
\text { Site } 3:-\end{array}$ & $\begin{array}{l}\text { Urban, coastal, and } \\
\text { high-relief forest } \\
\text { sites }\end{array}$ & $\begin{array}{l}\text { Site 1: low relief } \\
\text { Site 2: coastal barrier island } \\
\text { Site 3: high-relief forest }\end{array}$ & 3 \\
\hline [39] & First & 1 & 1 & $\begin{array}{l}\text { Site } 1: 1.3 \\
\text { Site } 2: 1.8 \\
\end{array}$ & $\begin{array}{l}\text { Site 1: urban } \\
\text { Site 2: forest }\end{array}$ & $\begin{array}{l}\text { Site 1: low-relief urban } \\
\text { Site 2: high-relief forest }\end{array}$ & 2 \\
\hline [12] & First & 5.6 & - & - & $\begin{array}{l}\text { Low-relief rural } \\
\text { sites }\end{array}$ & Low-relief areas with vegetation & 2 \\
\hline [44] & First & - & - & - & Urban and forest & $\begin{array}{l}\text { Site 1: flat, undulated terrain } \\
\text { Site 2: undulated terrain } \\
\text { Site 3: rough terrain, bushes+buildings }\end{array}$ & 3 \\
\hline [65] & First & - & - & - & $\begin{array}{l}\text { Low-relief forest } \\
\text { and railway }\end{array}$ & Forest areas with railways & 2 \\
\hline [54] & - & $>10$ & - & $\begin{array}{l}\text { Site 1: - } \\
\text { Site 2: } \\
0.01\end{array}$ & $\begin{array}{l}\text { High- resolution } \\
\text { LiDAR data }\end{array}$ & $\begin{array}{l}\text { Site 1: two buildings and forest } \\
\text { Site 2: roads, street lamps, an underpass, } \\
\text { and a small vegetation area }\end{array}$ & 2 \\
\hline [76] & - & 0.16 & - & - & $\begin{array}{l}\text { Low-relief with } \\
\text { trees and buildings }\end{array}$ & $\begin{array}{l}\text { Site 1: urban with large buildings } \\
\text { Site 2: low-relief, buildings and trees }\end{array}$ & 2 \\
\hline [42] & Second & $2-16$ & - & 0.01 & $\begin{array}{l}\text { High-resolution } \\
\text { LiDAR data }\end{array}$ & $\begin{array}{l}\text { Site 1: roads, street lamps, and underpass, } \\
\text { and a small vegetation area } \\
\text { Site } 2 \text { : forest site }\end{array}$ & 2 \\
\hline [58] & $\begin{array}{l}\text { First } \\
\text { or last }\end{array}$ & 0.77 & - & 0.65 & Forest & Forest with trees and buildings & 1 \\
\hline$[64]$ & $\begin{array}{l}\text { Site 1: } \\
\text { last } \\
\text { Site 2: } \\
\text { first+last }\end{array}$ & $\begin{array}{l}\text { Site } 1: 0.23 \\
\text { Site 2: } 0.81\end{array}$ & - & $\begin{array}{l}\text { Site 1: } 50 \\
\text { Site 2: } \\
6.25\end{array}$ & $\begin{array}{l}\text { Low-relief with } \\
\text { different features }\end{array}$ & $\begin{array}{l}\text { Low-relief with trees, buildings, and } \\
\text { railways }\end{array}$ & 2 \\
\hline$[66]$ & First+last & - & - & - & Forest & Forest site & 1 \\
\hline [43] & $\begin{array}{l}\text { First }+ \\
\text { last }\end{array}$ & 0.477 & - & 0.34 & $\begin{array}{l}\text { Low-relief urban } \\
\text { and forest sites }\end{array}$ & Urban and forest sites & 2 \\
\hline [1] & first & - & $1 \sim 2$ & - & $\begin{array}{l}\text { Various surfaces } \\
\text { from ISPRS }\end{array}$ & Urban and rural & 15 \\
\hline [21] & first & - & $1 \sim 2$ & - & $\begin{array}{l}\text { Various surfaces } \\
\text { from ISPRS }\end{array}$ & Urban and rural & 19 \\
\hline
\end{tabular}


The following elements are considerations for selecting study sites to test the reliability of ground filters.

1. Slope and Elevation Difference: Most filters make decisions based on a set of location specific thresholds. For example, the thresholds for the slope and elevation difference in low-relief urban areas are usually much smaller than those in high-relief forest area. If possible, researchers should test filters in both low- and high-relief areas.

2. Size of Objects: If the filters are sensitive to the size of objects, users can test the flexibility of filters using different object sizes such as large coastal boundaries and large or small buildings.

3. Surface Covering: It may be relatively easier to separate ground from non-ground in relatively flat areas covered with ground, trees, and buildings. However, an image containing a mixture of brush, short walls, and bridges can be much more troublesome. The complexity and spatial arrangement of objects covering the ground is another factor to consider when testing ground filter performance.

4. Density: It will likely be more difficult to identify ground points in an area covered by dense urban features, such as electric poles, flags and cars.

5. Size of Study Area: There are no criteria or restrictions in selecting the size of study sites, but areas that are too big may computationally too expensive to obtain optimal results. Study sites that are too small may overestimate filtering performance and mislead potential users of the filters. Table 1 indicates that areas around $1.5 \mathrm{~km}^{2}$ for one-meter resolution images may be an adequately sized area.

6. Number of Study Sites: Testing ground filtering algorithms in various conditions is critical for a fair evaluation. Most researchers listed in Table 1 selected at least two study sites with different characteristics for assessing performance. If developers test only one image, they should choose a relatively larger area to cover different terrain conditions.

\subsection{Accuracy Assessment}

Accuracy assessment plays an important role in both ground filtering applications and algorithm development [77]; however, quantitative accuracy assessment has been a challenge for LiDAR ground filtering due to the lack of ground truth data. Some researchers utilize visual inspection and others apply an approach similar to random sampling and cross-tabulation done in land-cover and land-use classification studies. Recent experiments, however, prove that accuracy assessment based on random sampling may lead to overestimating of ground filtering performance since most errors are distributed on object boundaries [1,57]. Hence, a review of accuracy assessment methods utilized in current publications is essential for the reference of future LiDAR data users.

There are three main categories of accuracy assessment methods, including visual inspection, random sampling of ground filtered data, and crosstabulation with classified ground truth data (Table 2). Visual inspection is a manual accuracy assessesment technique often used when ground truth data is unavailable. Visual inspection is appropriate for detecting obvious errors easily identifiable with the human eye. Visual inspection may vary by inspector. Some researchers utilize samples through visual interpretation or field survey to assist accuracy assessment. For example, studies have 
sampled [2,38,39] ground and non-ground polygons from filtered LiDAR data and compared them to ground reference data. Often, homogenous patches of ground and non-ground are selected. This approach is fast and convenient, but homogeneous regions are mainly found within easily recognizable patches, not on the edges of patches where most errors occur. In fact, recent studies find that errors are mainly found in difficult to recognize features, such as the bushes, short walls, and on the boundaries of the ground and non-ground objects. Therefore, the random sampling approach may lead to an overestimation of ground filtering performances. An alternative approach is to select a relatively smaller study sites, and then classify every pixel into ground and non-ground based on segmentation [57], field survey and manual editing. The International Society for Photogrammetry and Remote Sensing (ISPRS) has followed this approach by providing a set of testing sites containing various ground elements and a set of classified ground truth data. Researchers have adopted these same test sites to compare and evaluate different ground filtering algorithms $[1,21,60]$.

Table 2. Comparative table of accuracy assessment.

\begin{tabular}{|c|c|c|}
\hline Example & Ground truth data & Accuracy assessment \\
\hline$[2]$ & $\begin{array}{l}\text { Selected homogenous ground } \\
\text { and building polygons }\end{array}$ & Quantitative analysis \\
\hline [44] & 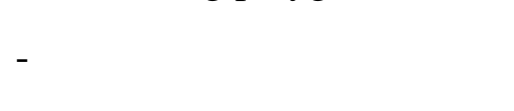 & $\begin{array}{l}\text { Quantitative analysis; total points; trend eliminated } \\
\text { points; eliminated points; type I and type II errors }\end{array}$ \\
\hline [38] & Random point samples & Quantitative analysis \\
\hline [39] & Random point samples & $\begin{array}{l}\text { Quantitative error analysis } \\
\text { Type I and type II errors }\end{array}$ \\
\hline$[1,21,60]$ & $\begin{array}{l}\text { Classified ground and non- } \\
\text { ground data for accuracy } \\
\text { assessment }\end{array}$ & $\begin{array}{l}\text { Quantitative analysis } \\
\text { Overall accuracy, Kappa co-efficient } \\
\text { Type I and type II errors }\end{array}$ \\
\hline$[12]$ & No sample & $\begin{array}{l}\text { Quantitative approach based on the filter property } \\
\text { that the classification results improve with the } \\
\text { point density }\end{array}$ \\
\hline [43] & No sample & Visual comparison, profile \\
\hline [58] & No sample & Visual comparison \\
\hline [42] & No sample & Visual comparison \\
\hline [54] & No sample & Visual comparison, profile analysis \\
\hline [64] & No sample & Visual comparison \\
\hline [65] & No sample & Visual comparison \\
\hline [76] & No sample & Visual comparison \\
\hline [66] & No sample & Visual comparison \\
\hline
\end{tabular}

\section{Review of Ground Filtering Methods}

\subsection{Ground Filtering Algorithms}

Researchers have developed a wide range of filters to separate ground from non-ground using LiDAR data [78]. Important considerations when selecting a ground filter include the number and type of LiDAR returns to use for ground filtering, the preprocessing steps, input data format, iterative characteristics, definition of neighborhoods, and other key factors applied in ground filtering process 
(Table 3). In the following paragraphs, we further classify these algorithms into six categories based on the characteristics of ground filters.

Table 3. Comparative table of key filter attributes.

\begin{tabular}{|c|c|c|c|c|c|c|c|}
\hline Publication & Return & Preprocess & Input & Filter & Iterative & Neighbor & Key factors \\
\hline [2] & First & - & Raw & $\begin{array}{l}\text { 1-D and bi-directional } \\
\text { labeling }\end{array}$ & No & $\begin{array}{l}\text { along scan } \\
\text { lines }\end{array}$ & $\begin{array}{l}\text { Slope } \\
\text { Elevation }\end{array}$ \\
\hline [38] & First & $\begin{array}{l}\text { Resampling } \\
\text { to raster- } \\
\text { lowest } \\
\text { elevation }\end{array}$ & Raw & $\begin{array}{l}\text { Compare three methods: } \\
\text { 1.elevation threshold } \\
\text { with expanding window } \\
\text { 2.maximum local slope } \\
\text { 3. Progressive } \\
\text { morphology }\end{array}$ & $\begin{array}{l}\text { Method } \\
\text { 1: yes } \\
\text { Method } \\
\text { 2: no } \\
\text { Method } \\
\text { 3: yes }\end{array}$ & $\begin{array}{l}\text { Method 1: } \\
\text { increased } \\
\text { mesh size } \\
\text { Method 2: } \\
\text { circle } \\
\text { Method 3: } \\
\text { increased } \\
\text { windows }\end{array}$ & $\begin{array}{l}\text { Method 1: } \\
\text { elevation } \\
\text { Method 2: } \\
\text { local slope } \\
\text { Method 3: } \\
\text { slope, } \\
\text { elevation, cell } \\
\text { size }\end{array}$ \\
\hline [39] & First & - & Interpolated & Progressive morphology & Yes & $\begin{array}{l}\text { Increased } \\
\text { windows }\end{array}$ & $\begin{array}{l}\text { Cell size, } \\
\text { slope, elevation }\end{array}$ \\
\hline [12] & First & $\begin{array}{l}\text { Delaunay } \\
\text { triangulation }\end{array}$ & Raw & $\begin{array}{l}\text { Erosion morphology and } \\
\text { elevation }\end{array}$ & No & $\begin{array}{l}\text { Predefined } \\
\text { circle }\end{array}$ & $\begin{array}{l}\text { Elevation, } \\
\text { slope }\end{array}$ \\
\hline [43] & $\begin{array}{l}\text { First } \\
+ \text { last }\end{array}$ & $\begin{array}{l}\text { Resampling } \\
\text { to raster }\end{array}$ & Raw & Cluster & No & $\begin{array}{l}\text { Voronoi } \\
\text { Neighbor }\end{array}$ & Elevation \\
\hline [44] & First & - & Interpolated & $\begin{array}{l}\text { Linear Prediction of } \\
\text { stationary random } \\
\text { function after trend } \\
\text { removal }\end{array}$ & Yes & $\begin{array}{l}\text { 2-D } \\
\text { window }\end{array}$ & Elevation trend \\
\hline$[58]$ & $\begin{array}{l}\text { First } \\
+ \text { last }\end{array}$ & - & Raw & $\begin{array}{l}\text { A despike VDF } \\
\text { algorithm } \\
\text { comparing local } \\
\text { curvatures of point } \\
\text { measurements }\end{array}$ & Yes & $\begin{array}{l}\text { Predefined } \\
\text { window }\end{array}$ & $\begin{array}{l}\text { Cell size, } \\
\text { elevation }\end{array}$ \\
\hline [42] & Second & $\begin{array}{l}\text { Resampling } \\
\text { to raster- } \\
\text { lowest }\end{array}$ & Raw & $\begin{array}{l}\text { Active contour and } \\
\text { active shape model }\end{array}$ & Yes & $\begin{array}{l}\text { Predefined } \\
\text { window }\end{array}$ & $\begin{array}{l}\text { Slope, } \\
\text { elevation, } \\
\text { energy function }\end{array}$ \\
\hline$[54]$ & - & $\begin{array}{l}\text { Resampling } \\
\text { to raster- } \\
\text { lowest }\end{array}$ & Raw & $\begin{array}{l}\text { Active shape model } \\
\text { based on energy function }\end{array}$ & Yes & $\begin{array}{l}\text { Predefined } \\
\text { window }\end{array}$ & $\begin{array}{l}\text { Slope, } \\
\text { elevation, } \\
\text { energy function }\end{array}$ \\
\hline$[64]$ & $\begin{array}{l}\text { First } \\
+ \text { last }\end{array}$ & - & Raw & $\begin{array}{l}\text { Iterative robust } \\
\text { interpolation }\end{array}$ & Yes & $\begin{array}{l}\text { Predefined } \\
\text { window }\end{array}$ & $\begin{array}{l}\text { Elevation } \\
\text { difference, } \\
\text { weight } \\
\text { assigned to } \\
\text { points }\end{array}$ \\
\hline$[65]$ & first & - & Raw & $\begin{array}{l}\text { Iterative robust } \\
\text { interpolation }\end{array}$ & Yes & $\begin{array}{l}\text { Predefined } \\
\text { window }\end{array}$ & $\begin{array}{l}\text { Elevation } \\
\text { difference, } \\
\text { weight } \\
\text { assigned to } \\
\text { points }\end{array}$ \\
\hline
\end{tabular}


Table 3. Cont.

\begin{tabular}{|c|c|c|c|c|c|c|c|}
\hline [76] & - & - & Raw & $\begin{array}{l}\text { A least-squares } \\
\text { adjustment with robust } \\
\text { estimation }\end{array}$ & Yes & $\begin{array}{l}\text { Predefined } \\
\text { window }\end{array}$ & $\begin{array}{l}\text { Slope, } \\
\text { elevation, } \\
\text { curvature }\end{array}$ \\
\hline [66] & $\begin{array}{l}\text { First } \\
+ \text { last }\end{array}$ & - & Raw & $\begin{array}{l}\text { A filter based on contour } \\
\text { and interpolation }\end{array}$ & Yes & $\begin{array}{l}\text { Predefined } \\
\text { window }\end{array}$ & elevation \\
\hline [21] & First & $\begin{array}{l}\text { Error } \\
\text { remove } \\
\text { Interpolation } \\
\end{array}$ & Interpolated & $\begin{array}{l}\text { Multi-sale Hermite } \\
\text { Transform }\end{array}$ & Yes & $\begin{array}{l}\text { Predefined } \\
\text { window }\end{array}$ & $\begin{array}{l}\text { Elevation, } \\
\text { slope }\end{array}$ \\
\hline [1] & First & $\begin{array}{l}\text { Error } \\
\text { remove } \\
\text { Interpolation }\end{array}$ & Interpolated & $\begin{array}{l}\text { Multi-directional } \\
\text { scanning combined with } \\
\text { the roving window } \\
\text { technique }\end{array}$ & Yes & $\begin{array}{l}\text { Predefined } \\
\text { window }\end{array}$ & $\begin{array}{l}\text { Slope, } \\
\text { elevation, the } \\
\text { nearest ground, } \\
\text { the label of the } \\
\text { previous pixel }\end{array}$ \\
\hline
\end{tabular}

Note: Publication — citation of literatures; Return —which returns are used in the paper; Preprocess: the preprocess researchers have utilized in the paper; Input - does the filter use raw LiDAR dataset or interpolated raster imagery; Filter-general description of the filter characteristics; Iterative-does the algorithm utilize iterative approaches; Neighbor — neighborhood definition; Key factors - major ground characteristic parameters used by the algorithm.

One of the first considerations when selecting a ground filtering algorithm is the optimal LiDAR return to use for filtering. Even when multiple LiDAR returns are available, most researchers choose the first return for ground filtering. Some forest researchers, however, choose the second return, last return, or a combination of the first and last returns because later returns penetrate the tree canopy and better represent the ground surface.

The technique for searching a local LiDAR neighborhood is another critical consideration in order to capture the height context of ground features. The height context is defined by a local neighborhood function, including linear neighborhoods along a directional scan line [2], circular neighborhoods for searching proximate points [38], and rectangular windows [39]. Studies have proven that the size of a two-dimensional neighborhood is critical for ground filtering performance [39,79]. Kilian and others proposed a method that works with different window sizes and assigns weights to each point within a neighborhood to determine the height context [39]. Other researchers [39] developed a progressive morphology with a gradually increased window size. In practice, most filtering algorithms iteratively modify the neighborhood size to improve filtering accuracy $[67,80]$.

Table 4. Classification of ground filters.

\begin{tabular}{lll}
\hline Class & Key methods & Examples \\
\hline \multirow{4}{*}{ Segmentation/Cluster } & Segmentation based on smoothness constraint & {$[81]$} \\
\cline { 2 - 3 } & Segmentation-based classification & {$[70,82]$} \\
\cline { 2 - 3 } & Segment-based terrain interpolation & {$[68]$} \\
\hline \multirow{3}{*}{ Morphology } & Dual rank filter based on dilation and erosion & {$[83]$} \\
\cline { 2 - 3 } & A morphological filer based on geodesic dilation & {$[63]$} \\
\cline { 2 - 3 } & Progressive morphological filter & {$[39]$} \\
\hline Directional Scanning & Bidirectional labeling & {$[2]$} \\
\hline
\end{tabular}


Table 4. Cont.

\begin{tabular}{lll}
\hline & \multicolumn{1}{l}{ Hybrid multi-directional ground filtering } & {$[24,57]$} \\
\hline \multirow{2}{*}{ Contour } & Active contour and active shape model & {$[42]$} \\
\cline { 2 - 3 } & Active shape model based on energy function & {$[54]$} \\
\hline \multirow{2}{*}{ TIN } & Local curvatures of point measurements & {$[58]$} \\
\cline { 2 - 3 } & The adaptive TIN model & {$[40,59]$} \\
\hline \multirow{3}{*}{ Interpolation } & The iterative robust interpolation & {$[64,65,66,76]$} \\
\cline { 2 - 3 } & The multiscale curvature algorithm based on TPS interpolation & {$[67]$} \\
\cline { 2 - 3 } & A facet model & {$[50]$} \\
\cline { 2 - 3 } & Linear prediction & {$[84,85]$} \\
\hline
\end{tabular}

\section{Segmentation- and Cluster-based Filters}

Segmentation and clustering are popular techniques for land-use and land-cover classification, and researchers have been trying to implement this approach to separate discrete LiDAR point clouds $[69,81,86,87]$. For example, Filin [82] performed a clustering classification to separate ground features into four types using point position information, elevation difference to neighbors, and parameter description from the point to its tangent plane. Jacobsen and Lohmann [70] applied the segmentation method from the e-cognition software to classify LiDAR data into seven classes to separate terrain points. Tóvári and Pfeifer [68] proposed a segmentation-based ground filtering method that includes two major steps. A segmentation process is first initialized by a region growing method from an automatically selected ground seed. Then the method gradually adds neighbor points based on three mathematical measurements of the points to the mathematical plane represented by points in a segment and eventually separates LiDAR point clouds into segments that are corresponding to surface objects. The second stage utilizes those segments as basic elements for a least-square linear interpolation by incorporating an adaptive weight function to minimize the weights for segments from non-ground objects. Experiments on a small and relative flat area with two buildings showed that this method overestimated non-ground surface by showing upward curve in building area. This was partly because non-ground objects participated in the surface interpolation with a smaller weight instead of being removed. Many segmentation and cluster-based filtering experiments are carried out on relatively flat ground surface $[68,70,82,86]$. Further experiments on more complicated surfaces with rough terrain are necessary to evaluate the performance because surfaces with less homogenous height texture could be challenging for these methods.

\section{Morphological Filters}

Mathematical morphology deals with object shape or shape measurement [88], and experiments on LiDAR data have shown that a morphological filter has the ability to remove non-ground objects, such as buildings and trees [24,39,46,61,63,83]. Typical processes include opening, closing, dilatation and erosion based on kernel operators [4,83]. For example, Lohmann [83] tested a dual rank filter [89] that involves morphological dilation and erosion to mask out non-ground candidate for removal. The authors reported promising results for this method but limitations for requiring knowledge for study sites and interactive process. 
Many morphological filters suffered difficulties in removing different sizes of objects with a fixed widow size [38]. To solve the problem, Arefi and Hahn [63] developed a morphological method based on geodesic dilation and changing window sizes to gradually remove non-ground points and rebuild terrain surface. The results show that the selection of window sizes is critical to removing objects with different sizes, such as large buildings. Zhang et al. [39] proposed a progressive morphological filter by gradually increasing the size of the windows [39]. Another study [38] compared the algorithm with another maximum local slope filter and elevation-based filter with an expanding window. The results showed that the progressive morphological filter produced the least error among the three methods. The progressive morphological filter also demonstrated a better ability to preserve the boundary of objects that are larger than the window size [38]. Chen et al. [61] developed a morphology-based methods based on opening operation to gradually remove non-ground using a gradually increased window size. Additionally, the authors proposed a two step process to further minimize the limitation of window size. The algorithm first removes most forest points using a relatively small window iteration, then repeats the filtering process with larger windows to further screen large buildings.

\section{Directional Scanning Filters}

Most ground filters define neighborhood in a two dimensional space [12,38,39,58], but few methods calculate slope and elevation difference along a one-dimensional scan line. Shan and Sampath [2] developed a bidirectional algorithm to remove non-ground points based on slope and elevation difference calculated along the scan line with additional reference to the nearest ground-labeled point and the label of the previous point along the scan line. Instead of referring to the estimated values based on surrounding points, this bidirectional method compares points with their immediate neighbors and has been proven to be sensitive in removing low vegetation [57]. However, the directional methods are sometimes sensitive to sudden ground surface change and create artificial lines across ground surfaces [1,57].

To overcome this problem, Meng et al. [1,57] developed a multi-directional ground filtering (MGF) algorithm by combining the directional scanning with two-dimensional neighborhood searches after transforming point clouds into raster data. Therefore, this algorithm is actually a hybrid method of directional scanning and two-dimensional kernel-based approach. As a result, the experiments prove that the MGF algorithm has an improved ability to preserve object shape (i.e., reduce of errors within objects) and is sensitive to low vegetation yet robust to threshold selection [1,57]. Furthermore, this hybrid method overcomes the common problem of those methods that are based on two-dimensional estimation and require changing window sizes to remove objects with different sizes. An uncertainty test shows that the MGF algorithm works well under a three-by-three window and is not sensitive to building sizes [1,57].

\section{Contour-Based Filters}

An active shape model is one of the methods used for contour mapping [90,91] and has been recently introduced to LiDAR-based terrain mapping through active contours [42,54]. This algorithm utilizes the active shape model to represent a three-dimensional contour, which functions like a net to gradually remove non-ground points based on force measurements such as gravitation and attraction. 
The contour-based filters provide a unique alternative for LiDAR ground surface mapping; however, further steps should be taken to test their performance in various surface conditions and compare with existing algorithms.

\section{TIN-Based Filters}

An iterative TIN-based filter, called the despike Virtual Deforestation (VDF) algorithm, removes non-ground points based on the smoothness of ground [58]. This algorithm assumes that ground areas are usually smooth surfaces without sharp corners in bare terrain surfaces. Therefore, points with strong curvatures were defined as non-ground points. Based on a point database, this method first builds a TIN model and then makes two conversions. One is to convert the TIN model into a point database. The other is to convert the TIN model into a grid, calculate the mean value within a $3 \times 3$ window, and assign the mean value to the central pixel. Curvatures were defined as the mean value minus the corresponding value in the point database converted from the TIN model. There are two thresholds, one of which is to eliminate those points above terrain that have a strong curvature, and the other one is for removing the "negative blunders" [58]. Based on these thresholds, the filter labels the recognizable non-ground points for deletion and builds a new TIN based on the filtered ground points and repeats the labeling process until no more points are removed.

This filter can utilize the first, last, or multiple returns. The results showed that the filter successfully removed small buildings and most bridges but failed to remove some large and low buildings. This was because the filter used a fixed window size to calculate the mean values and failed to remove those objects larger than the window size. It also failed to remove some "negative blunders" that were usually extremely low values comparing to local points and are often removed as noise in some preprocesses.

An active-TIN based model developed by Axelsson [40,59] recently draws attention through a comparative study based on eight ground filtering algorithms [60]. Similarly, this TIN-based method utilizes a TIN surface to iteratively estimate ground surface. The algorithm gradually removes non-ground points based on the elevation difference and angle to the closest triangle. Furthermore, the method generates adaptive thresholds based on the updated ground points for each iterative process instead of a global one $[40,59,60]$. The experiments based on fifteen study sites prove that this active-TIN based method present the best performance in terms of average overall accuracy [60]. Similar results were reported when comparing this method to two other methods [1,21].

\section{Interpolation-Based Filters}

The main principle of interpolation-based approaches is to compare the elevation of points with its estimated values through various interpolation methods. Researchers who adopt linear interpolation methods often need to apply an iterative processing strategy to minimize the influence of local non-ground points [83]. For example, Kraus and others [25,65,66] presented an iterative approach based on a linear least-square interpolation with a set of adaptive weight functions. The concept of changing weight supports its robust nature in various conditions. Researchers have successfully tested this filter in a mapping project [76], in applications with both forests and break lines [66] and build-up areas [64], and improved the filter for applications in forest areas [66]. Studies have reported limitation 
when trying to apply these methods to surface with rough terrain and steep ground slope [4,84] and developed an improved version to suite steep areas [84].

Another optional interpolation method is the thin-plate spline (TPS) model [92,93]. Evans and Hudak [67] incorporated a multi-scale iterative filtering process using the TPS interpolation by changing interpolation cell size. Results showed improvement in removing understory vegetation. A new method estimating ground elevations based on Hermite transformation applies the similar multi-resolution strategy through the iterative process [21]. Other interpolation methods include facet model [50] and statistics methods such as minimum values [38].

\subsection{Comparative Studies and the MGF Algorithm}

The number and variety of ground filters can make it difficult to select the best filter for a particular study site. To date, there has been relatively little comparison of ground filters because filters are often developed for particular study sites or terrain conditions. Many algorithms were originally tested on relatively small study sites with little topographic variation (Table 2) and their appropriateness for other regions is unclear [94]. An exception to this trend is the comparisons [1,21,60] made using the International Society for Photogrammetry and Remote Sensing (ISPRS) standardized LiDAR and ground reference data $[1,21]$ for fifteen study sites with unique terrain conditions. Comparisons using these datasets are reviewed below and compared to the MGF algorithm developed by the authors using the ISPRS data.

Sithole and Vosselman [60] tested eight ground filtering algorithms on twelve ISPRS datasets. They reported that most filters performed well on relative flat and smooth surfaces, but that all have noticeable errors in regions with urban structures or abrupt slope changes or a complex vegetation covering. Their findings indicate that performance evaluations based on simple sites are insufficient to prove the ability of ground filters. Three methods outperformed the other five filters in terms of average overall accuracy, including a linear prediction method, an adaptive slope filter, and a morphological filter [1,21]. Results from this report led to two other filter comparisons based on the same data [1,21]. These comparisons test the multi-scale Hermite transform (MHT) filter and the multi-directional ground filtering (MGF) algorithm. Another study applied three ground filters [95,96] based on five sites from the ISPRS websites. Their results showed that the performance varied with surface types and covering, but one of the methods generated highest type I errors (mis-label of ground as non-ground) in four of the five sites.

In our previous research [1], we developed the MGF algorithm and compared its performance with eight other methods based on published comparative results [60] using the fifteen standardized datasets. Figures 1, 2, and 3 are the MGF ground filtering results without an optimizing process on the fifteen study sites presented in our previous study [1] and demonstrate various ground characteristics and surface conditions. The average overall accuracy of the MGF algorithm is lower than Axelsson's filter [40] but higher than the other seven algorithms (Figure 3). Four of the nine algorithms achieved accuracies above $70 \%$. In testing the MGF algorithm, comparisons were made between filtering results obtained using one set of parameters and results obtained using unique parameters urban and forest sites. All accuracies were very high indicating that the MGF filter was robust to parameter selection and insensitive to the selection of scanning directions. Additionally, the MGF algorithm functions 
especially well in urban areas because it is sensitive to short vegetations and other non-ground objects [1,57].

Figure 1. Error distribution for city sites 1-4. Each image is displayed at a unique scale (source [1]).
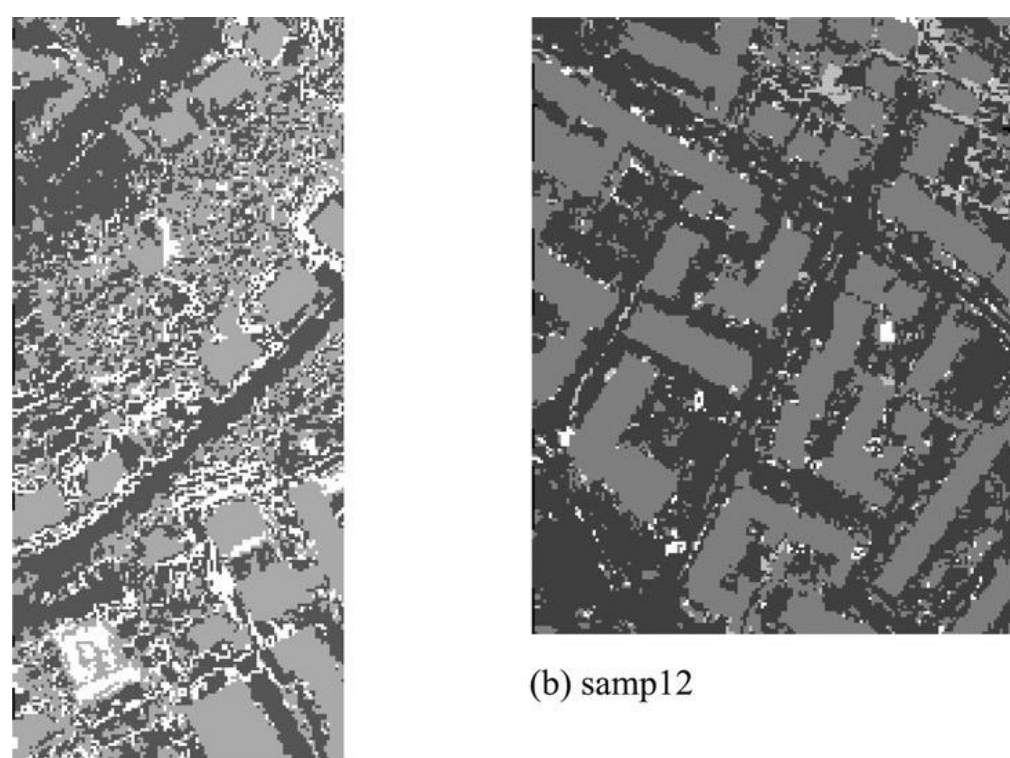

(b) samp12

(a) samp11

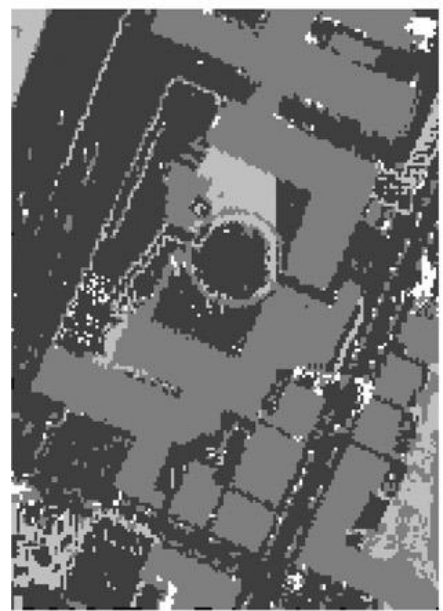

(e) samp23

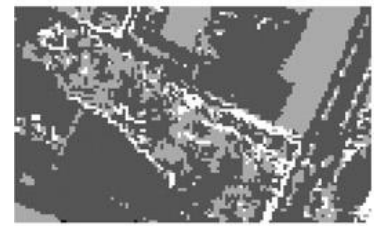

(h) samp24

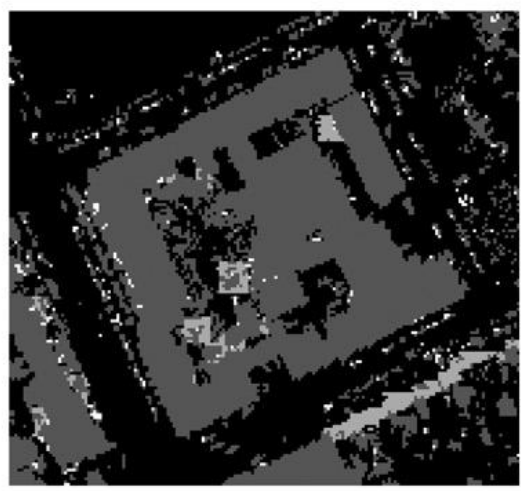

(f) samp31

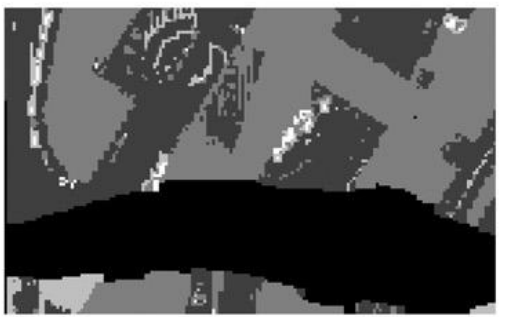

(i) samp41

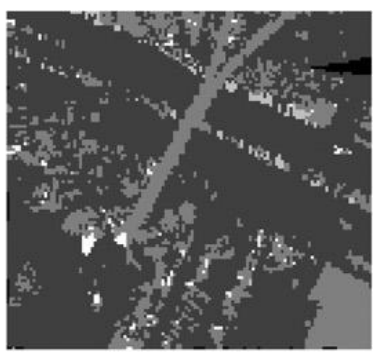

(c) samp21

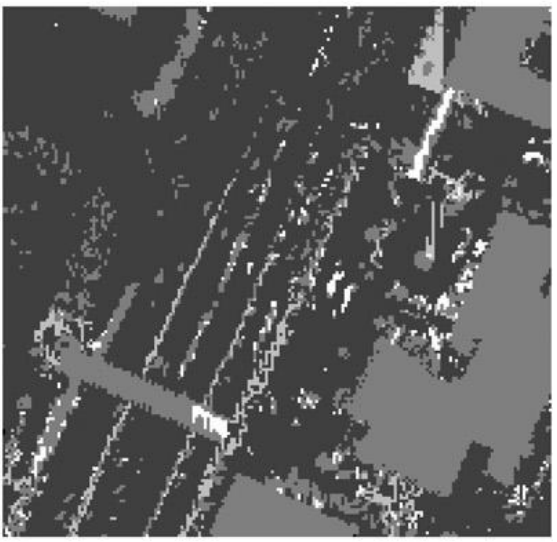

(d) samp22

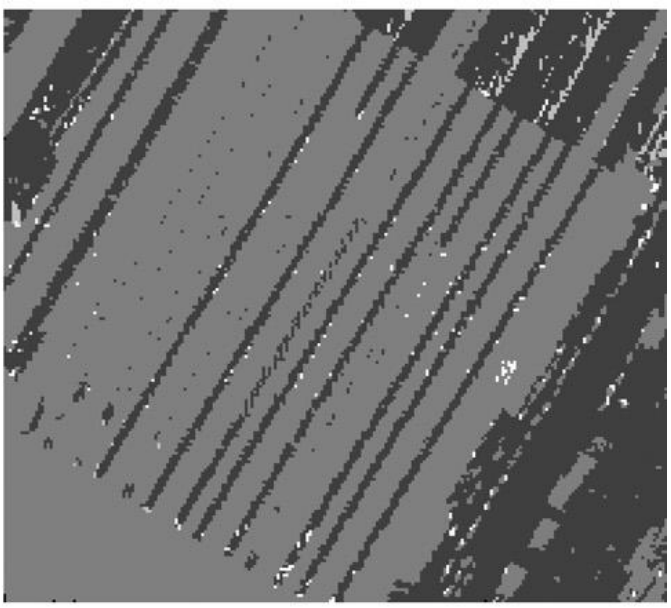

(g) samp42

Ground

Non-ground

Type I error

Type II error 
Figure 2. Error distribution for forest sites 5-7. Each image is displayed at a unique scale (source [1]).

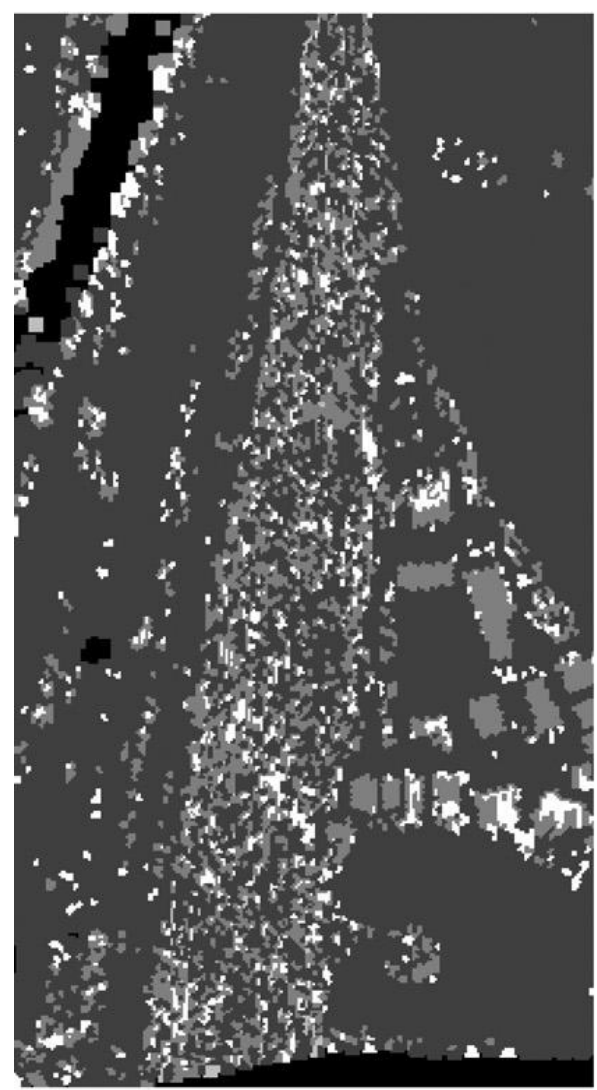

(a) samp51

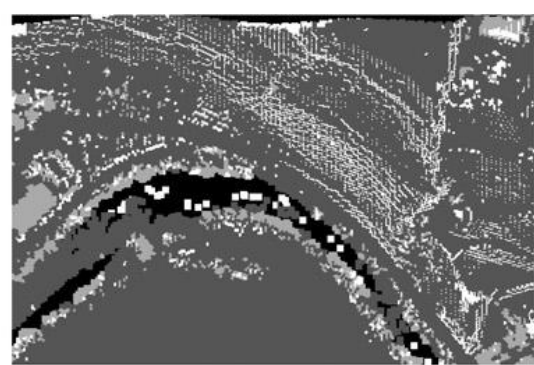

(b) samp52

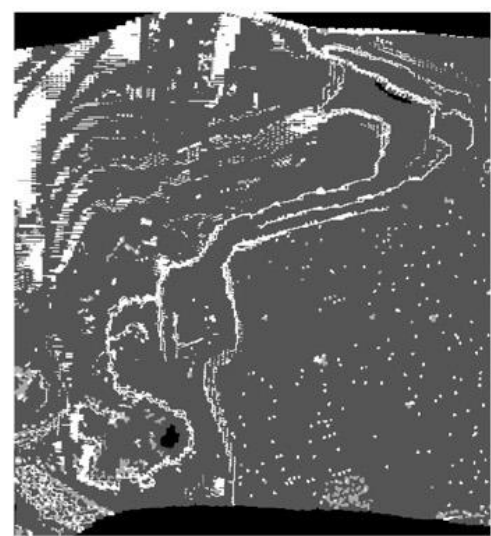

(c) samp53

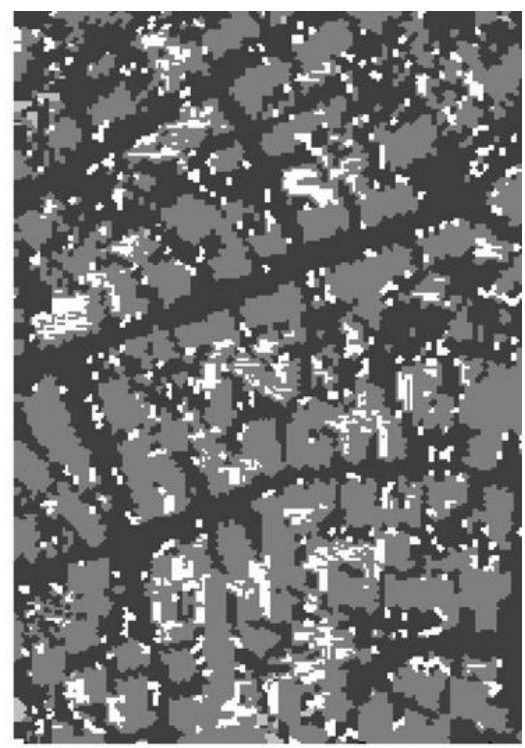

(d) samp54

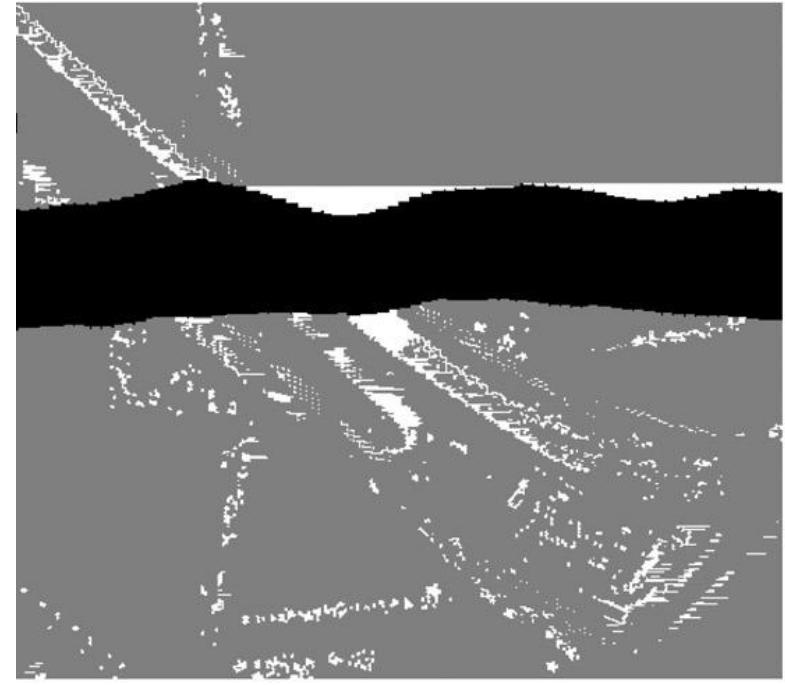

(e) samp61

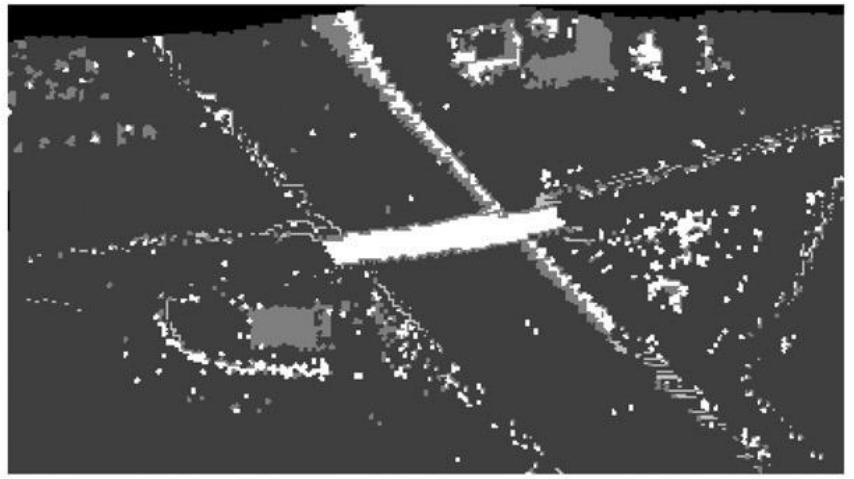

(f) samp71

Ground

Type I error

Non-ground

Type II error 
Figure 3. Kappa averages on fifteen sites for nine filters (source [1]).

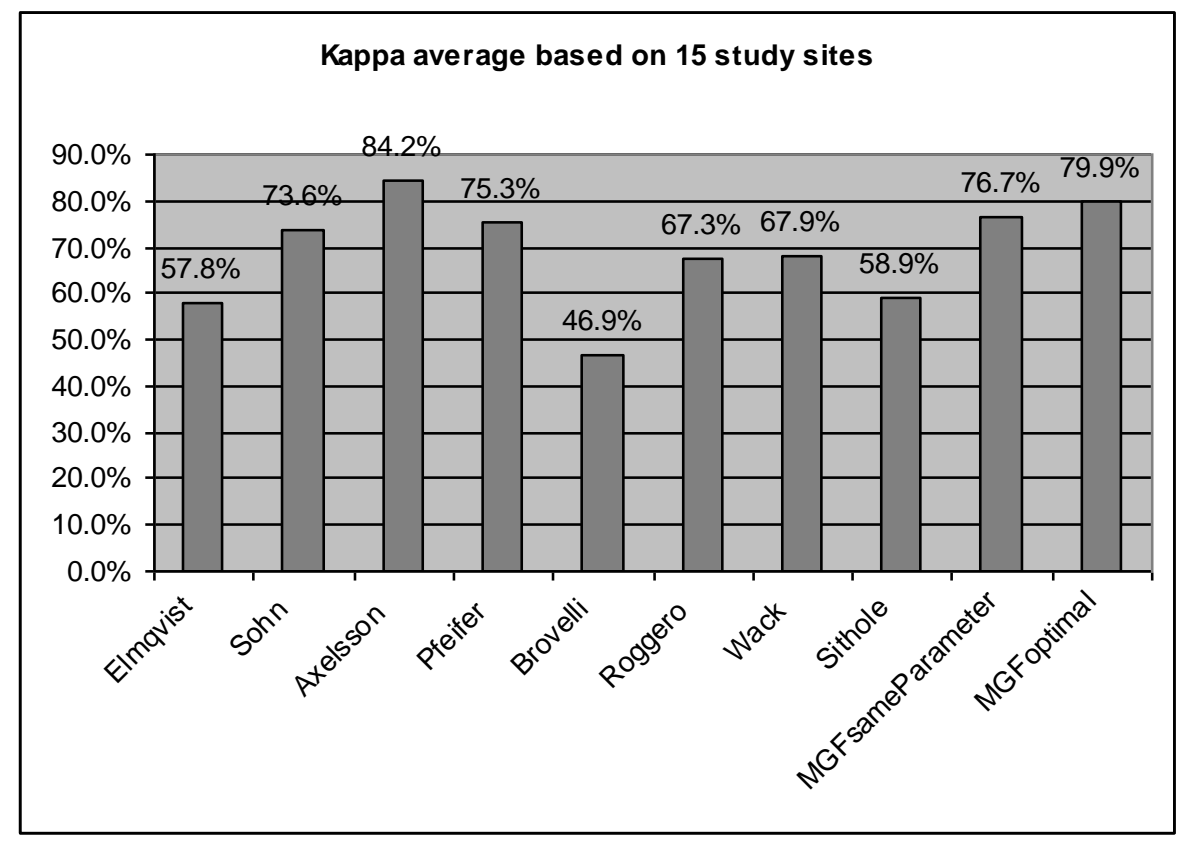

Due to the variety of possible ground characteristics and complex surface coverings, statistics on average overall accuracy of ground filtering algorithms may not provide much guidance to users studying areas with dense vegetation or rough terrain. Therefore, we divide the fifteen ISPRS study sites into three groups (sites with rough slope and dense vegetation, sites with relatively flat urban areas containing objects of various size and shape, and sites with rough terrain and discontinuous surfaces like river banks and mining fields) and provide results for nine algorithm for each category of terrain (Figures 4-6). Figure 4 shows that in an environment with steep slope and trees, Axelsson's filter generated the best performance on site 11 and 24 followed by the MGF algorithm. The MGF algorithm performs the best in site 41 that is an urban environment with dense trees and less-intensive slope. Site 54 is a relative flat urban environment with dense trees and is typical in residential areas in developed countries. The Axelsson's filter produces the best result in this site. The MGF algorithm may produce comparable results if care is taken to accurately the necessary parameters. The decrease in the non-optimized applications of the MGF algorithm is caused by applying the same parameters to sub-sites 5 through 7. These results show that in an urban environment with dense trees and steep slope the Axelsson's filter and the MGF filter provide more accurate results.

Figure 5 shows the performance in a regular urban environment with less intensive slope and trees but more irregular ground surface covering. The accuracy results vary with surface cover conditions in each case, but three methods (Axelsson, Pfeifer, and MGF) generate comparable results on most urban sites. Additionally, the MGF algorithm provides the best performance in urban areas with long linear features like bridges and railroad stations (see sites 21 and 42). Figure 6 shows the performance in environments with abrupt ground slope changes and discontinuous surfaces. Axelsson's filter dominants each ground filtering test on five sites and the performance of the remaining filters varies with surface conditions. The Sohn, MGF, Pfeifer, and Roggero filters provide comparable results for surfaces with abrupt slope and discontinuous. 
Besides LiDAR ground filtering algorithm comparison, comparative studies between difference sensors are critical issues for LiDAR industry and user guidance. Typical topics include the comparison between LiDAR, traditional photogrammetry, and SAR [15]. Habib et al. [15] provided an overview of the general comparison between LiDAR and photogrammetry in various aspects from sensor or mission design to critical elements in applications. This comparative study analyzed the strengths and weaknesses for both approaches and concluded that both techniques were fairly competitive and the integration of both approach might improve accuracy or generate new products [15]. Zhang and Whitman [38] compared an elevation-based filter using gradually increased window sizes, a slope-based method, and a progressive morphology method through urban and coastal sites. The experiments showed that the morphology filter performed better in the coastal site, and all three filtering methods were mostly sensitive to the slope parameter.

Figure 4. Accuracies of nine ground filters on sites with steep slope and trees.

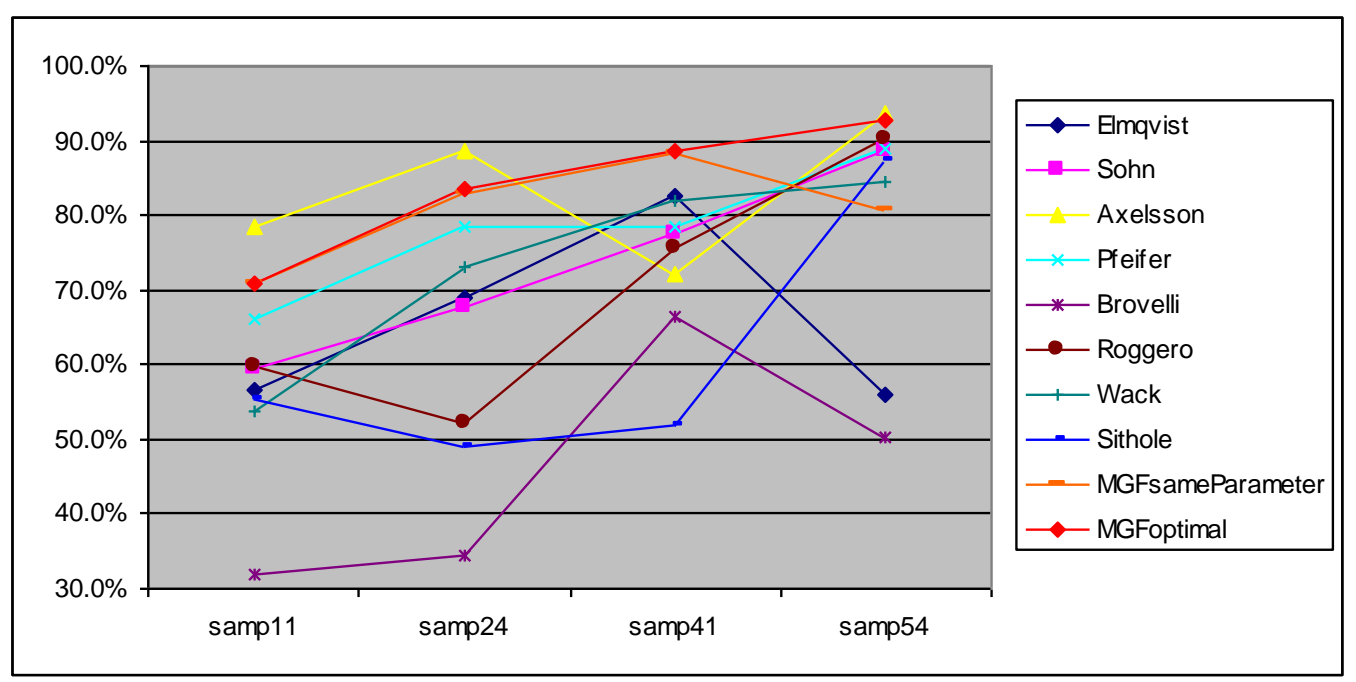

Figure 5. Accuracies of nine ground filters on relative flat urban sites that contain objects with various size and shape.

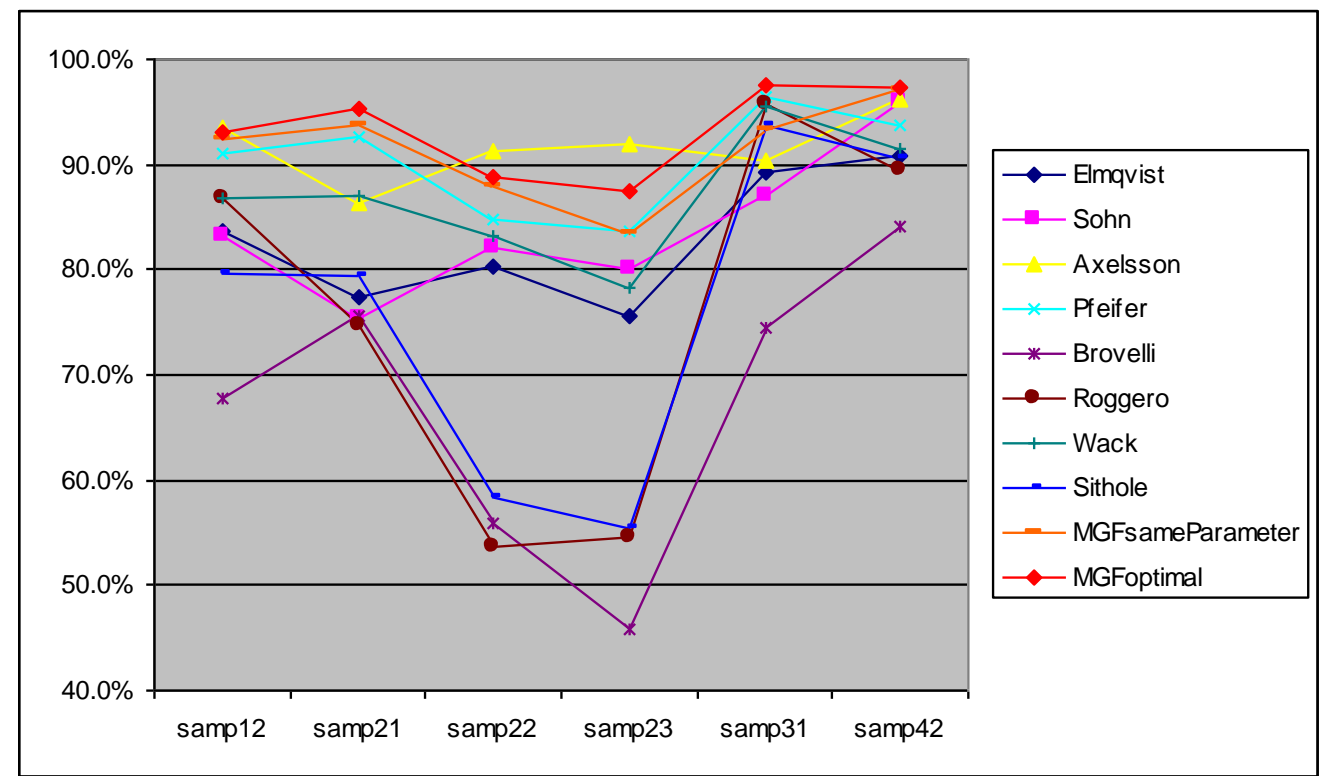


Figure 6. Accuracies of nine ground filters on sites with rough terrain or discontinuous surfaces.

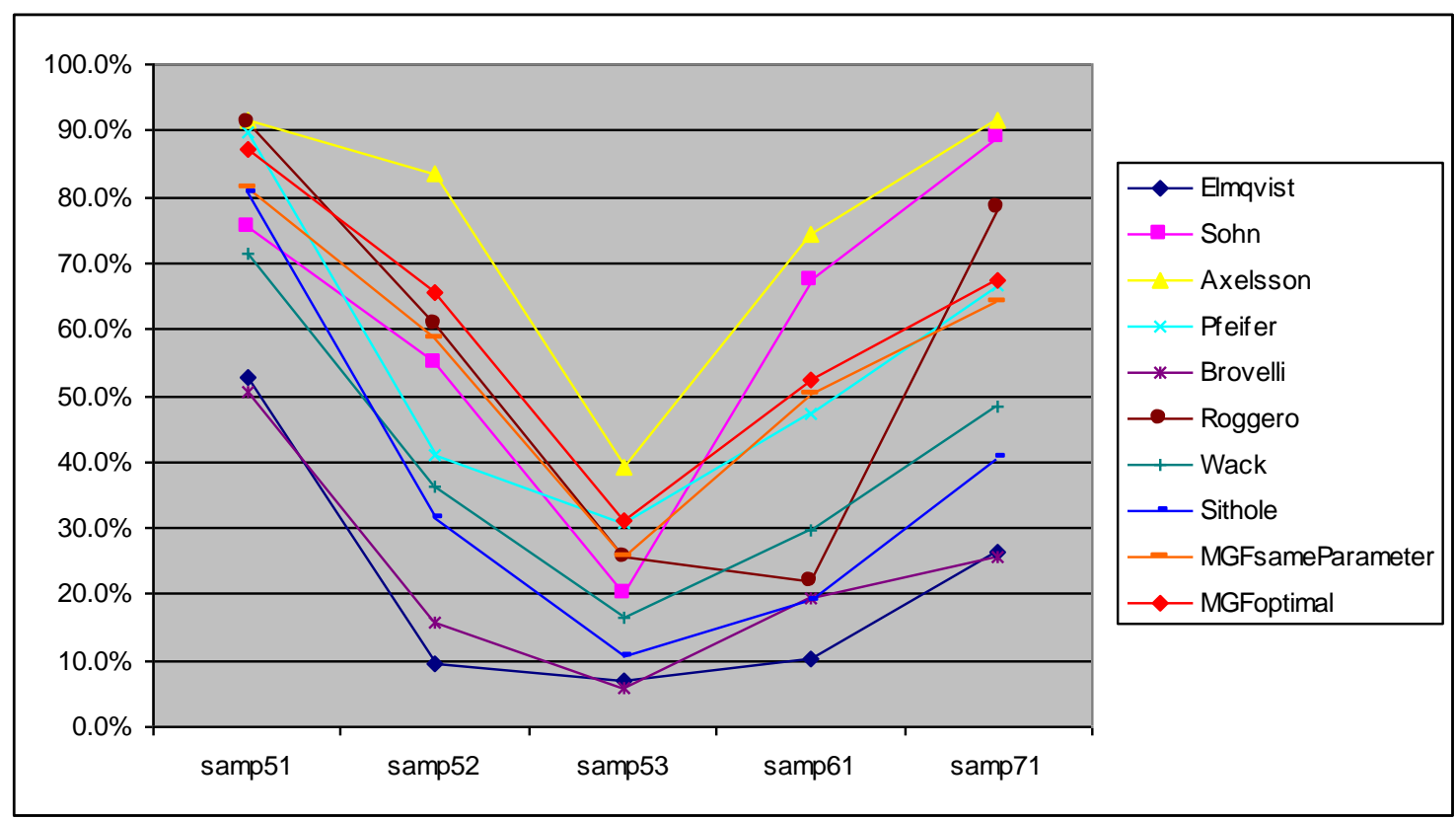

\subsection{Factors Affecting Accuracy of Ground Filtering or Terrain Modeling}

\section{Interpolation Methods}

Interpolation methods are one of the major sources that contribute to the accuracy of ground surface estimation [97,98], which affect either point-raster transformation through preprocess or terrain interpolation based on ground-labeled points or pixels [1,57]. An interpolation comparative study [97] based on points from field survey on a bare ground smooth surface evaluated six types of interpolation methods and found that the spline interpolation produced the best results. Smith et al. [99] studied the influence of different interpolation methods to digital surface modeling (including objects above terrain) based on LiDAR dataset. Such experiments are useful guidance for the selection of interpolation preprocess. Their results indicated that the nearest neighbor interpolation generated the highest overall error for surface modeling and introduced sudden ground surface changes that might not present in original data. Furthermore, ordinary kriging interpolation presented more errors than bilinear and cubic methods and showed limitation in urban areas with man-made objects. Negative results for biharmonic spline showed overshooting problem for areas with low point density, especially on edges.

\section{Resolution}

In order to examine the influence of cell size to terrain estimation, Kienzle [100] conducted DEM interpolation experiments using ground elevation point samples (100-meter space) derived from photogrammetry to interpolate DEMs with 5 to 100-meter resolutions. The results showed that DEMs with 5 to 20-meter resolution better represented local elevation. Another study showed that increasing DEM cell size can reduce errors of the products generated from the DEM [101] while losing detail information. 


\section{Density and Data Reduction}

LiDAR data with high density point clouds provide more detailed information for ground features; however, the massive information sometimes create problems for data storage and feature extraction, which is similar to the problem with high-resolution photogrammetry [73,102,103]. Hence, some LiDAR applications require data reduction to reduce data size while keeping comparable accuracy $[102,103]$.

Anderson et al. [102] evaluated the influence of point density to DEMs with 5-, 10-, and 30-meter cell sizes based on five subset point clouds reduced to 1-50 percent. Results showed that DEMs with higher resolutions were more sensitive to LiDAR point density, which meant requiring higher density for optimal performance. The authors found these evaluations useful to determine the minimum point density given selected DEM resolution. Another experiment [73] examined the influence of point density to linear interpolation methods such as inverse distance and kriging interpolation. The results proved that it was possible to reduce point density but maintain a satisfactory DEM estimation, and complicated interpolation methods do not necessary produce superior results. Liu et al. [103] extended this discussion by combining similar analysis with data storage and computing time. Results showed that data with $50 \%$ reduction provided compatible surface estimation but significantly reduced half of the processing time and storage space. Sithole and Vosselman [60] examined the influence of data reduction to the performance of eight ground filtering algorithms in terms of type I and type II errors. The results did not show universal patterns between rates of reduction and accuracies, rather the effects varied with the characteristics of ground filters. Furthermore, the results showed that data reduction did not necessarily cause lower accuracies.

\section{Post-Spacing}

Raber et al. [104] evaluated the influence of LiDAR post spacing to hydrological modeling. Results showed that the flood zone base terrain showed no significant change but the flood plain boundary calculation was more sensitive to post spacing.

\section{Original Data Error Caused by Instrument, Sensor or Non-surface features}

Some random errors from original LiDAR data may come from instruments such as cameras and GPS, or other non-surface features such as birds and some floating objects [105]. The possible source of errors are commonly discussed during error filtering preprocess [1,21,57]. Besides, systematic error may occur in interpolated DEM as artificial lines due to the height difference of flight lines [106]. Hyyppä et al. [106] also pointed out the significant shift of systematic errors between different returns.

\section{Use of First or Last Return for Ground Filtering}

One important debate for ground filtering is the selection of LiDAR first or last returns for ground filtering $[21,24,57,106]$. Some researchers select the last return because the last pulses reach deeper in vegetated areas and hence are closer to ground surface $[43,58,66]$; while others argue that some pulses from the last return may reach lower part of objects instead of ground, which will introduce errors 
when wrongly classified as ground [1,24,57]. Such concern is less significant in urban studies and more substantial in forested areas as demonstrated in Table 1.

\section{Conclusions}

LiDAR analysis has attracted much attention in recent decades, and ground filtering is the primary step required for DEM generation or ground feature identification. Numerous researchers have developed algorithms to identify ground surfaces, but until now no comprehensive comparative review of available methods has been made to guide potential users in selecting a proper method for a specific study site. This paper not only categorizes LiDAR ground filtering algorithms for various applications and surface types, but also outlines common processes and critical considerations that users face during practical implementations.

Current ground filters commonly utilize four ground characteristics to separate ground from non-ground features: lowest feature in a specific area, ground slope threshold, ground surface elevation difference threshold, and smoothness. LiDAR ground filters commonly build upon the ground slope and ground elevation difference thresholds. Some directional filtering methods make additional references to the label of previous points in a scan line and the elevation of the nearest ground points found in previous iterations. Many iterative algorithms require a ground seed as a primary ground elevation reference to initiate the filtering process, and researchers commonly utilize the lowest feature characteristic to locate these ground seeds. When utilizing such filters, special concern should be given to error filtering to remove potential outliers with unreasonably low values. If this preprocessing step is not taken, the algorithms may end up finding no ground points as the slope and elevation are much higher than the defined thresholds.

Whether to perform ground filtering based on the first or last return is another critical decision to make in most LiDAR applications. Some researchers prefer the last return for ground filtering because laser beams penetrate deeper in vegetated areas, but others worry that the last return may introduce errors from the returns of lower parts of vegetation. This review finds that most urban applications are less concerned about this issue and simply using the first return since less trees are usually present in an urban setting compared to a forest. Forest researchers, however, use the last return because it penetrates the tree canopy and more points returns from the ground surface. Additoinally, quantitative accuracy assessment remains a challenging task due to the fact that most ground filtering errors are located on object boundaries. As a result, visual inspection and accuracy assessment based on traditional random sampling may overestimate ground filtering performance. Thus, most LiDAR data users are faced with manually generating classified ground truth data based on image interpretation and field surveys. Because this approach is time-consuming for large areas, the ISPRS provides several reliable sites with ground truth data to test algorithms in different surface conditions. Once validated, algorithms can be applied to other study sites.

Future LiDAR studies need to focus on the development of methods that resolve three remaining ground filtering challenges. Ground filtering algorithms continue to have difficulty performing well with three ground surface types: (1) surfaces with rough terrain or discontinuous slope, (2) dense forest canopies that reduce the penetration of laser beams [107], and (3) regions with low vegetation that is often ignored by many ground filters [1,47,57,108,109]. Researchers have suggested that large 
footprint LiDAR may be one of the solutions for terrain mapping in dense forested areas because those laser beams have higher chance to reach ground [107]. For some deciduous forests, seasonal difference in LiDAR data or data collected during the leaf-off period might be worthwhile for improving terrain mapping in dense forests [28]. Empirical analysis regarding the selection of the first or last returns for forest studies is necessary to determine which return is optimal. Additionally, more algorithm comparative studies and uncertainty analysis should be carried out in more specialized areas such as low vegetation and coastal areas to provide clearer guidance for specific users since comparative studies based on mixed surface types often exhibit mixed spatial patterns and LiDAR signals.

\section{References}

1. Meng, X.; Wang, L.; Silván-Cárdenas, J.L.; Currit, N. A multi-directional ground filtering algorithm for airborne LIDAR. ISPRS J. Photogramm. Remote Sens. 2009, 64, 117-124.

2. Shan, J.; Sampath, A. Urban DEM generation from raw LiDAR data: a labeling algorithm and its performance. Photogramm. Eng. Remote Sens. 2005, 71, 217-226.

3. Sithole, G. Filtering of laser altimetry data using a slope adaptive filter. Int. Arch. Photogramm. Remote Sens. 2001, 34-3/W4, 203-210.

4. Liu, X. Airborne LiDAR for DEM generation: some critical issues. Prog. Phys. Geog. 2008, 32, 31-49.

5. Baligh, A.; Valadan Zoej, M.J.; Mohammadzadeh, A. Bare earth extraction from airborne lidar data using different filtering methods. In Proceedings of Commission III, ISPRS Congress Beijing 2008, Beijing, China, July 2008.

6. Kukko, A.; Hyyppä, J. Small-footprint laser scanning simulator for system validation, error assessment, and algorithm development. Photogramm. Eng. Remote Sens. 2009, 75, 1177-1189.

7. Hill, J.M.; Graham, L.A.; Henry, R.J.; Cotter, D.M.; Ping, A.; Young, P. Wide-area topographic mapping and applications using airborne light detection and ranging (LiDAR) technology. Photogramm. Eng. Remote Sens. 2000, 66, 908-914.

8. Lohr, U. Digital elevation models by laser scanning. Photogramm. Rec. 1998, 16, 105-109.

9. Kilian, J.; Haala, N.; Englich, M. Capture and evaluation of airborne laser scanner data. Int. Arch. Photogramm. Remote Sens. Spatial Inf. Sci. 1996, 31, 383-388.

10. Mandlburger, G.; Briese, C.; Pfeifer, N. Progress in LiDAR sensor technology — chance and challenge for DTM generation and data administration. In Proceedings of 51st Photogrammetric Week 2007, Stuttgart, Germany, 2007; pp. 159-169.

11. Pfeifer, N.; Stadler, P.; Briese, C. Derivation of digital terrain models in the SCOP++ environment. In Proceedings of OEEPE Workshop on Airborne Laser Scanning and Interferometric SAR for Digital Elevation Models, Stockholm, Sweden, 2001.

12. Vosselmann, G. Slope based filtering of Laser altimetry data. Int. Arch. Photogramm. Remote Sens. 2000, XXXIII, 935-942.

13. Petzold, B.; Reiss, P.; Stossel, W. Laser scanning - surveying and mapping agencies are using a new technique for the derivation of digital terrain models. ISPRS J. Photogramm. Remote Sens. 1999, 54, 95-104. 
14. Reutebuch, S.E.; Andersen, H.-E.; McGaughey, R.J. Light detection and ranging (LIDAR): an emerging tool for multiple resource inventory. J. Forest. 2001, 103, 286-292.

15. Baltsavias, E. A comparison between photogrammetry and laser scanning, ISPRS J. Photogramm. Remote Sens. 1999, 54, 83-94.

16. Brovelli, M.A.; Cannata, M.; Longoni, U.M. LiDAR data filtering and DTM interpolation within GRASS. Trans. GIS 2004, 8, 155-174.

17. Wehr, A.; Lohr, U. Airborne laser scanning-an introduction and overview. ISPRS J. Photogramm. Remote Sens. 1999, 54, 68-82.

18. Luzum, B.J.; Slatton, K.C.; Shrestha, R.L. Identification and analysis of airborne laser swath mapping data in a novel feature space. IEEE Geosci. Remote Sens. Lett. 2004, 1, 268-271.

19. Romano, M.E. Innovation in LiDAR processing technology. Photogramm. Eng. Remote Sens. 2004, 70, 1202-1206.

20. Flood, M. Laser altimetry - from science to commercial lidar mapping. Photogramm. Eng. Remote Sens. 2001, 67, 1209-1211.

21. Silván-Cárdenas, J.L.; Wang, L. A multi-resolution approach for filtering LiDAR altimetry data. ISPRS J. Photogramm. Remote Sens. 2006, 61, 11-22.

22. Habib, A.; Ghanma, M.; Morgan, M.; Al-Ruzouq, R. Photogrammetric and lidar Data Registration Using Linear Features. Photogramm. Eng. Remote Sens. 2005, 71, 699-707.

23. Lin, Y.; Mills, J.P. Factors influencing pulse width of small footprint, full waveform airborne laser scanning data. Photogramm. Eng. Remote Sens. 2010, 76, 49-59.

24. Meng, X.; Wang, L.; Currit, N. Morphology-based building detection from airborne LIDAR data. Photogramm. Eng. Remote Sens. 2009, 75, 427-442.

25. Kraus, K.; Pfeifer, N. Determination of terrain models in wooded areas with aerial laser scanner data. ISPRS J. Photogramm. Remote Sens. 1998, 53,193-203.

26. Stoker, J.M.; Greenlee, S.K.; Gesch, D.B.; Menig, J.C. CLICK: the new USGS center for LiDAR information coordination and knowledge. Photogramm. Eng. Remote Sens. 2006, 72, 613-616.

27. Raber, G.T.; Jensen, J.R.; Schill, S.R.; Schuckman, K. Creation of Digital Terrain Models using an adaptive Lidar vegetation point removal process. Photogramm. Eng. Remote Sens. 2002, 68, 1307-1316.

28. Hodgson, M.E.; Jensen, J.; Raber, G.; Tullis, J.; Davis, B.A.; Thompson, G.; Schuckman, K. An evaluation of LiDAR-derived elevation and terrain slope in leaf-off condition. Photogramm. Eng. Remote Sens. 2005, 71, 817-823.

29. Popescu, S.; Zhao, K. A voxel-based lidar method for estimating crown base height for deciduous and pine Trees. Remote Sens. Environ 2008, 112, 767-781.

30. Zhao, K.; Popescu, S. Lidar-based mapping of leaf area index and its comparison with satellite GLOBCARBON LAI Products. Remote Sens. Environ. 2009, 113, 1628-1645.

31. Zhao, K.; Popescu, S.; Nelson, R. Lidar remote sensing of forest biomass: a scale-invariant approach using airborne lasers. Remote Sens. Environ. 2009, 112, 182-196.

32. Kraus, K.; Otepka, J. DTM modelling and visualization - the SCOP approach. In Proceedings of Photogrammetric Week 05, Heidelberg, Germany, 2005; pp. 241-252.

33. Alharthy, A.; Bethel, J. Heuristic filtering and $3 \mathrm{~d}$ feature extraction from lidar data. In Proceedings of PCV02, Graz, Austria, 2002. 
34. Ma, R.; Meyer, W. DTM generation and building detection from Lidar data. Photogramm. Eng. Remote Sens. 2005, 71, 847-854

35. Aumann, G.; Ebner, H.; Tang, L. Automatic derivation of skeleton lines from digitized contours. ISPRS J. Photogramm. Remote Sens. 1991, 46, 259-268.

36. Cho, W.; Jwa, Y.; Chang, H.; Lee, S. Pseudo-grid based building extraction using airborne LIDAR data. Int. Arch. Photogramm. Remote Sens. 2004, 35, 378-381.

37. Sohn, G.; Dowman, I. Data fusion of high-resolution satellite imagery and LiDAR data for automatic building extraction. ISPRS J. Photogramm. Remote Sens. 2007, 62, 43-63.

38. Zhang, K.; Whitman, D. Comparison of three algorithms for filtering airborne LiDAR data. Photogramm. Eng. Remote Sens. 2005, 71, 313-324.

39. Zhang, K.; Chen, S.; Whitman, D.; Shyu, M. A progressive morphological filter for removing nonground measurements from airborne LiDAR data. IEEE Trans. Geosci. Remote Sens. 2003, $41,872-882$.

40. Axelsson, P. Processing of laser scanner data-algorithms and applications. ISPRS J. Photogramm. Remote Sens. 1999, 54, 138-147.

41. Masaharu, H.; Ohtsubo, K. A filtering method of airborne laser scanner data for complex terrain. Int. Arch. Photogramm. Remote Sens. Spatial Inf. Sci. 2002, XXXIV, 165-169.

42. Elmqvist, M.; Jungert, E.; Lantz, F.; Persson, A.; Soderman, U. Terrain modelling and analysis using laser scanner data. Int. Ach. Photogramm. Remote Sens. 2001, XXXIV, 211-218.

43. Okagawa, M. Algorithm of multiple filter to extract DSM from LiDAR data. In Proceedings of 2001 ESRI International User Conference, ESRI, San Diego, CA, USA, 2001.

44. Passini, R.; Jacobsen, K. Filtering of digital elevation models. In Proceedings of the ASPRS 2002 Annual Convention, [CD-ROM], Washington, DC, USA, April 2002; p. 9.

45. Arefi, H.; Engels, J.; Hahn, M.; Mayer, H. Automatic DTM generation from laser-scanning data in residential hilly area. In Proceedings of ISPRS Joint Workshop: "Visualization and Exploration of Geospatial Data”, Stuttgart, Germany, June 2007.

46. Kobler, A.; Pfeifer, N.; Ogrinc, P.; Todorovski, L.; Oštir, K.; Džeroski, S. Repetitive interpolation: a robust algorithm for DTM generation from aerial laser scanner data in forested terrain. Remote Sens. Environ. 2007, 108, 9-23.

47. Wang, C; Menenti, M.; Stoll, M.P.; Alessandra, F; Enrica, B.; Marco, M. Separation of Ground and Low Vegetation Signatures in LiDAR Measurements of Salt-Marsh Environments. IEEE Trans. Geosci. Remote Sens. 2009, 47, 2014-2023.

48. Yang, X. Use of LiDAR elevation data to construct a high-resolution digital terrain model for an estuarine marsh area. Int. J. Remote Sens. 2005, 26, 5163-5166.

49. Lloyd, C.D.; Atkinson, P.M. Deriving ground surface digital elevation models from LiDAR data with geostatistics. Int. J. Geogr. Inf. Sci. 2006, 20, 535-563.

50. Zheng, S.; Shi, W.; Liu, J.; Zhu, G. Facet-based airborne light detection and ranging data filtering method. Opt. Eng. 2007, 46, doi: 10.1117/12.760080.

51. Nardinocchi, C.; Forlani, G.; Zingaretti, P. Classification and filtering of laser data. In Proceedings of the ISPRS working group III/3 workshop "3-D Reconstruction from Airborne Laser Scanner and InSAR Data”, Dresden, Germany, October 2003. 
52. Wack, R.; Wimmer, A. Digital Terrain Models from Airborne Laser scanner Data—a Grid Based Approach. In Proceedings of ISPRS Commission III, Symposium 2002, Graz, Austria, September 2002; pp. 293-296.

53. Hyyppa, J.; Pyysalo, U.; Hyyppa, H.; Samberg, A. Elevation accuracy of laser scanning-derived digital terrain and target models in forest environment. In Proceedings of EARSeL-SIG-Workshop LIDAR, Dresden, Germany, June 2000.

54. Elmqvist, M. Ground surface estimation from airborne laser scanner data using active shape models. In Proceedings of ISPRS Commission III Symposium, Photogrammetric and Computer Vision, Graz, Austria, 2002; pp. 114-118.

55. Lloyd, C.D.; Atkinson, P.M. Deriving DSMs from LiDAR data with kriging. Int. J. Remote Sens. 2002, 23, 2519-2524.

56. Reutebuch, S.E.; McGaughey, R.J.; Andersen, H.E.; Carson, W.W. Accuracy of a high-resolution lidar terrain model under a conifer forest canopy. Can. J. Remote Sens. 2003, 29, 527-535.

57. Meng, X. A slope- and elevation-based filter to remove non-ground measurements from airborne LIDAR data. In Proceedings of ISPRS WG III/3, III/4, V/3 Workshop "Laser scanning 2005", The Netherlands, September 2005; p. 23.

58. Haugerud, R.A.; Harding, D.J. Some algorithms for virtual deforestation (VDF) of LiDAR topographic survey data. Int. Arch. Photogramm. Remote Sens. 2001, XXXIV, 219-226.

59. Axelsson, P. DEM Generation from Laser Scanner Data Using Adaptive TIN Models, Int. Arch. Photogramm. Remote Sens. 2000, XXXIII, 110-117.

60. Sithole, G.; Vosselman, G. Experimental comparison of filter algorithms for bare earth extraction from airborne laser scanning point clouds. ISPRS J. Photogramm. Remote Sens. 2004, 59, 85-101.

61. Chen, Q.; Gong, P.; Baldocchi, D.D.; Xie, G. Filtering airborne laser scanning data with morphological methods. Photogramm. Eng. Remote Sens. 2007, 73, 175-185.

62. Gonçalves-Seco, L.; Miranda, D.; Crecente, F.; Farto, J. Digital terrain model generation using airborne LiDAR in a forested area Galicia, Spain. In Proceedings of 7th International symposium on spatial accuracy assessment in natural resources and environmental sciences, Lisbon, Portugal, 2006; pp. 169-180.

63. Arefi, H.; Hahn, M. A morphological reconstruction algorithm for separating off-terrain points from terrain points in laser scanning data. In Proceedings of the ISPRS Workshop Laser Scanning, Enschede, The Netherlands, September 2005.

64. Briese, C.; Pfeifer. N. Airborne laser scanning and derivation of digital terrain models. In Proceedings of Fifth Conference on Optical 3-D Measurement Techniques, Vienna, Austria, 2001.

65. Kraus, K.; Pfeifer, N. Advanced DTM generation from LiDAR data. In Proceedings of the ISPRS Workshop on Land Surface Mapping and Characterization Using Laser Altimetry; Hofton, M.A., Ed.; Annapolis, MD, USA, 2001.

66. Kraus, K.; Rieger, W. Processing of laser scanning data for wooded areas. In Photogrammetric Week'99, Fritsch, D., Spiller, R., Eds.; Wichmann Verlag: Stuttgart, Germany, 1999; pp. 221-231.

67. Evans, J.S.; Hudak, A.T. A multiscale curvature algorithm for classifying discrete return LiDAR in forested environments. IEEE Trans. Geosci. Remote Sens. 2007, 45, 1029-1038. 
68. Tóvári, D.; Pfeifer, N. Segmentation based robust interpolation-a new approach to laser filtering. Int. Arch. Photogramm. Remote Sens. Spatial Inf. Sci. 2005, 36, 79-84.

69. Filin, S.; Pfeifer, N. Segmentation of airborne laser scanning data using a slope adaptive neighborhood. ISPRS J. Photogramm. Remote Sens. 2009, 60, 71-80.

70. Jacobsen, K.; Lohmann, P. Segmented filtering of laser scanner DSMs. In Proceedings of the ISPRS Working Group III/3 workshop '3-D Reconstruction From Airborne Laserscanner and InSAR Data', Dresden, Germany, October 2003.

71. Ali, T.A. On the selection of an interpolationmethod for creating a terrain model (TM) from LIDAR data. In Proceedings of the American Congress on Surveying and Mapping (ACSM) Conference 2004, Nashville, TN, USA, 2004.

72. Chaplot, V.; Darboux, F.; Bourennane, H.; Leguédois, S.; Silvera, N.; Phachomphon, K. Accuracy of interpolation techniques for the derivation of digital elevation models in relation to landform types and data density. Geomorphology 2006, 77, 126-141.

73. Anderson, E.S.; Thompson, J.A.; Austin, R.E. LiDAR density and linear interpolator effects on elevation estimates. Int. J. Remote Sens. 2005, 26, 3889-3900.

74. Almansa, A.; Cao, F.; Gousseau, Y.; Rougé, B. Interpolation of digital elevation models using AMLE and related methods. IEEE Trans. Geosci. Remote Sens. 2002, 40, 314-325.

75. Shi, W.Z.; Tian, Y. A hybrid interpolation method for the refinement of a regular grid digital elevation model. Int. J. Geogr. Inf. Sci. 2006, 20, 53-67.

76. Schickler, W.; Thorpe, A. Surface estimation based on LiDAR. In Proceedings of ASPRS Annual Conference, St. Louis, MO, USA, April 2001.

77. Hodgson, M.E.; Bresnahan, P. Accuracy of airborne Lidar-derived elevation: empirical assessment and error budget, Photogramm. Eng. Remote Sens. 2004, 70, 331-339.

78. Jenkins, L.G. Key drivers in determining LiDAR sensor selection. In Proceedings of ISPRS Commission VII Mid-Symposium 'Remote Sensing: from Pixels to Processes', Enschede, The Netherlands, 2006; pp. 342-357.

79. Whitman, D.; Zhang, K.; Leatherman, S.P.; Robertson, W. Airborne laser topographic mapping: application to hurricane storm surge hazards. In Earth Science in the Cities: A Reader; Heiken, G., Fakundiny, R., Sutter, J., Eds.; American Geophysical Union: Washington, DC, USA, 2003, pp. 363-376.

80. Crosilla, F.; Visintini, D.; Prearo, G. A robust method for filtering non-ground measurements from airborne LiDAR data. Int. Arch. Photogramm. Remote Sens. Spatial Inf. Sci. 2004, XXXV, 196-201.

81. Rabbania, T.; van den Heuvelb, F.A.; Vosselmanc, G. Segmentation of point clouds using smoothness constraint. Int. Arch. Photogramm. Remote Sens. Spatial Inf. Sci. 2006, 36, 248-253.

82. Filin, S. Surface clustering from airborne laser scanning data. Int. Arch. Photogramm. Remote Sens. Spatial Inf. Sci. 2002, XXXIV, 119-124.

83. Lohmann, P.; Koch, A.; Schaeffer, M. Approaches to the filtering of laser scanner data. Int. Arch. Photogramm. Remote Sens. 2000, 33, 540-547.

84. Lee, H.S.; Younan, N.H. DTM extraction of LiDAR returns via adaptive processing. IEEE Trans. Geosci. Remote Sens. 2003, 41, 2063-2069. 
85. Pfeifer, N.; Reiter, T.; Briese, C.; Rieger, W. Interpolation of high quality ground models from laser scanner data in forested areas. Int. Arch. Photogramm. Remote Sens. Spatial Inf. Sci. 1999, 32, 31-36.

86. Roggero, M. Airborne laser scanning: clustering in raw data. Int. Arch. Photogramm. Remote Sens. Spatial Inf. Sci. 2001, XXXIV, 227-232.

87. Sithole, G.; Vosselman, G. Filtering of airborne laser scanner data based on segmented point clouds. In Proceedings of ISPRS Workshop Laser Scanning 2005, Enschede, the Netherlands, September 2005; pp. 66-71.

88. Harlick, R.M.; Shapiro, L.G. Computer and Robot Vision; Addison-Wesley: Reading, MA, USA, 1992.

89. Eckstein, W.; Munkelt, O. Extracting objects from digital terrain models. Proc. SPIE 1995, 2572, 43-51.

90. Kass, M.; Witkin, A.; Terzopoulos, D. Snakes: active contour models. Int. J. Comput. Vision 1998, 1, 321-331.

91. Cohen, L.D.; Cohen, I. Finite element methods for active contour models and balloons for 2D and 3D images. IEEE Trans. Patt. Anal. Mach. Int. 1991, 15, 1131-1147.

92. Briggs, I. Machine contouring using minimum curvature. Geophysics 1974, 39, 39-48.

93. Jain, R.; Kasturi, R.; Schunck, B. G. Machine Vision; McGraw-Hill: New York, NY, USA, 1995.

94. Sithole, G. Filtering strategy: working towards reliability. In Proceedings of PCV 02, ISPRS Commission III, Symposium 2002, Graz, Austria, September 2002; pp. 330-335.

95. Sohn, G.; Dowman, I. Terrain surface reconstruction by the use of tetrahedron model with the MDL Criterion. In Proceedings of PCV 02, ISPRS Commission III, Symposium 2002, Graz, Austria, September 2002; pp. 336-344.

96. Hu, Y. Automated Extraction of Digital Terrain Models, Roads and Buildings Using Airborne Lidar Data. Available online: http://www.geomatics.ucalgary.ca/links/GradTheses.html (accessed on 30 April 2009)

97. Desmet, P.J.J. Effects of interpolation errors on the analysis of DEMs. Earth Surf. Processes Landf. 1997, 22, 563-580.

98. Crombaghs, M.; Elberink, S.O.; Brügelmann, R.; de Min, E. Assessing Height Precision of Laser Altimetry DEMs. In Proceedings of PCV 02, ISPRS Commission III, Symposium 2002, Graz, Austria, September 2002; pp. 85-90.

99. Smith, S.L.; Holland, D.A.; Longley, P.A. Quantifying interpolation errors in urban airborne laser scanning models. Geogr. Analysis 2005, 37, 200-224.

100. Kienzle, S. The effect of DEM raster resolution on first order, second order and compound terrain derivatives. Trans. GIS 2004, 8, 83-111.

101. Albani, M.; Klinkenberg, B.; Andison, D.W.; Kimmins, J.P. The choice of window size in approximating topographic surfaces from digital elevation models. Int. J. Geogr. Inf. Sci. 2004, 18, 577-593.

102. Anderson, E.S.; Thompson, J.A.; Crouse, D.A.; Austin, R.E. Horizontal resolution and data density effects on remotely sensed LIDAR- based DEM. Geoderma 2005, 132, 406-415. 
103. Liu, X.; Zhang, Z.; Peterson, J.; Chandra, S. The effect of LiDAR data density on DEM accuracy. In Proceedings of International Congress on Modelling and Simulation (MODSIM07), Christchurch, New Zealand, 2007; pp. 1363-1369.

104. Raber, G.T.; Jensen, J.R.; Hodgson, M.E.; Tullis, J.A.; Davis, B.A.; Berglend, J. Impact of LiDAR nominal post-spacing on DEM accuracy and flood zone delineation. Photogramm. Eng. Remote Sens. 2007, 73, 793-804.

105. Huising, E.J.; Gomes Pereira, L.M. Errors and accuracy estimates of laser data acquired by various laser scanning systems for topographic applications. ISPRS J. Photogramm. Remote Sens. 1998, 53, 245-261.

106. Hyyppä, J.; Yu, X.; Rönnholm, P.; Kaartinen, H.; Hyyppä, H. Factors affecting laser-derived object-oriented forest height growth estimation. Photogramm. J. Fin. 2003, 18, 16-31.

107. Dubayah, R.O.; Drake, J.B. LiDAR remote sensing for forestry. J. Forest. 2000, 98, 44-46.

108. Pfeifer, N.; Gorte, B.; Oude Elberink, S. Influences of vegetation on laser altimetry-analysis and correction approaches. In ISPRS Working Group VIII/2 'Laser-Scanners for Forest and Landscape Assessment', Freiburg, Germany, 2004; pp. 283-287.

109. Montané, J.M.; Torres, R. Accuracy assessment of LiDAR saltmarsh topographic data using RTK GPS. Photogramm. Eng. Remote Sens. 2006, 72, 961-967.

(C) 2010 by the authors; licensee Molecular Diversity Preservation International, Basel, Switzerland. This article is an open-access article distributed under the terms and conditions of the Creative Commons Attribution license (http://creativecommons.org/licenses/by/3.0/). 